\title{
EL TRIBUNAL DE JUSTICIA DE LA UNIÓN EUROPEA FRENTE A LA RELIGIÓN Y LAS CREENCIAS
}

\author{
RAFAEL PALOMINO LOZANO' \\ Universidad Complutense de Madrid \\ rafaelpalomino@ucm.es
}

\author{
Cómo citar/Citation \\ Palomino Lozano, R. (2020). \\ El Tribunal de Justicia de la Unión Europea frente a la religión y las creencias. \\ Revista de Derecho Comunitario Europeo, 65, 35-77. \\ doi: https://doi.org/10.18042/cepc/rdce.65.02
}

\section{Resumen}

En apenas dos años, el Tribunal de Justicia de la Unión Europea ha conocido numerosos asuntos relacionados con la religión y las creencias. Con ello se han visto superadas las antiguas referencias consolidadas sobre este tema (Van Duyn, Prais...) acerca del papel del derecho fundamental de libertad religiosa, o de la religión en general, en el ordenamiento de la Unión Europea. El presente trabajo tiene por objeto extraer algunas conclusiones acerca del tratamiento otorgado a la religión y a las creencias por el Tribunal de Justicia de la Unión Europea. Para ello, se examina en primer lugar la religión y las creencias en el derecho primario, marco y presupuesto de posteriores derivaciones normativas, estudiando inmediatamente después las resoluciones del TJUE que guardan relación con la religión y las creencias en el periodo comprendido entre 1974 y 2019. Del análisis efectuado se concluyen algunas notas acerca del concepto de religión en la jurisprudencia del Tribunal de Luxemburgo, así como de la formulación y contenido del principio de neutralidad religiosa. En general, salvo en supuestos puntuales, el Tribunal de Justicia de la Unión Europea otorga una protección adecuada al derecho fundamental de libertad religiosa y un tratamiento ajustado a los grupos religiosos respecto de las exigencias del derecho europeo.

1 Catedrático de Derecho Eclesiástico del Estado, Universidad Complutense de Madrid. 


\title{
Palabras clave
}

Tribunal de Justicia de la Unión Europea; libertad religiosa; no discriminación; confesiones religiosas.

\section{THE COURT OF JUSTICE OF THE EUROPEAN UNION CONFRONTS RELIGION AND BELIEFS}

\begin{abstract}
In just two years, the Court of Justice of the European Union has been faced with numerous issues related to religion and beliefs. With this, the old consolidated references on this subject (Van Duyn, Prais...) about the role of the fundamental right of religious freedom, or about religion in general, in the European Union system have been surpassed. The aim of this paper is to draw some conclusions about how the Court of Justice of the European Union deals with religion and beliefs. To this purpose, religion and beliefs in primary law, which is framework and condition to subsequent normative implications, are examined firstly. Several decisions related to religion or beliefs in the period between 1974 and 2019 are analysed afterwards. The analysis carried out concludes with some notes about the concept of religion in the jurisprudence of the Luxembourg Court, as well as about the formulation and content of the principle of religious neutrality. In general, exception made of specific cases, the Court of Justice of the European Union grants adequate protection to the fundamental right of religious freedom and an adjusted treatment to religious groups with respect to the requirements of European Law.
\end{abstract}

\section{Keywords}

Court of Justice of the European Union; Religious freedom; Non-discrimination; Religious groups.

\section{LA COUR DE JUSTICE DE L'UNION EUROPÉENNE CONFRONTE RELIGION ET CROYANCES}

\section{Résumé}

En à peine deux ans, la Cour de justice de l'Union européenne a pris connaissance de plusieurs affaires liées à la religion et aux croyances. De ce fait, elle a cessé de recourir aux vieilles références habituelles (Van Duyn, Prais...) sur les questions relatives au rôle du droit fondamental de liberté religieuse, ou plus largement de la religion, au sein de l'ordre juridique européen. Le présent travail a pour objectif de mettre en évidence certaines conclusions relatives au traitement accordé par la Cour 
de justice de l'Union européenne à la religion et aux croyances. Pour ce faire, la religion et les croyances seront en premier lieu examinées dans le droit primaire, le cadre et la prémisse des dérivations normatives postérieures; succédées par l'étude de décisions judiciaires, en lien avec la religion et les croyances, rendues entre 1974 et 2019. De l'analyse globale effectuée, quelques conclusions, relatives aux traitements du concept de religion et du principe de neutralité religieuse dans la jurisprudence de la Cour, seront proposées. En général, malgré quelques cas isolés, il est possible d'affirmer que la Cour de justice de l'Union européenne garanti une protection adéquate du droit fondamental de liberté religieuse, ainsi qu'un traitement adapté aux groupes religieux, tout en respectant les exigences du droit européen.

\section{Mots clés}

Cour de justice de l'Union européenne; liberté religieuse; absence de discriminations; confessions religieuses. 


\section{SUMARIO}

I. INTRODUCCIÓN. II. RELIGIÓN Y CREENCIAS EN EL DERECHO ORIGINARIO:

1. Una perspectiva jurídica orgánica. 2. Una perspectiva dogmática: el derecho fundamental de libertad religiosa. III. LA JURISPRUDENCIA DEL TRIBUNAL DE JUSTICIA DE LA UNIÓN EUROPEA SOBRE RELIGIÓN Y CREENCIAS: 1. Primeras sentencias y decisiones conexas. 2. Derecho europeo y actividad económica de grupos religiosos. 3. Religión y no discriminación: 3. 1. Discriminación y símbolos o vestuario religioso. 3.2. Discriminación de empleados por parte de las confesiones religiosas. 3.3. Discriminación por motivos religiosos de empleados en virtud de normas estatales. 4. Otras cuestiones: asilo, derecho de familia, datos personales y prescripciones alimentarias. IV. CONCLUSIONES: ALGUNOS RASGOS DESTACABLES DE LA JURISPRUDENCIA EN TORNO A LA RELIGIÓN Y LAS CREENCIAS. BIBLIOGRAFíA.

\section{INTRODUCCIÓN}

En apenas dos años, el Tribunal de Justicia de la Unión Europea (en adelante, TJUE) ha conocido numerosos asuntos relacionados con la religión y las creencias. Con ello se han visto superadas las antiguas referencias (Van Duyn, Prais...) acerca del papel del derecho fundamental de libertad religiosa, o de la religión en general, en el ordenamiento de la Unión Europea.

El presente trabajo tiene por objeto extraer algunas conclusiones acerca del tratamiento otorgado a la religión y a las creencias por el TJUE. Para ello, se examina en primer lugar la religión y las creencias en el derecho primario, marco y presupuesto de posteriores derivaciones normativas, estudiando inmediatamente después las resoluciones del TJUE (sentencias y autos) que guardan relación con la religión o las creencias entre 1974 y 2019.

Hasta el momento, la mayoría de los trabajos de investigación acerca de la jurisprudencia del TJUE sobre esta temática han comentado algunas sentencias concretas, recurriendo también a la jurisprudencia del Tribunal Europeo de Derechos Humanos (en adelante TEDH) como instrumento de comparación (Iglesias Vázquez, 2015). En este trabajo se intenta abarcar toda la jurisprudencia del TJUE en la que el fenómeno religioso resulta relevante, reduciendo en lo posible las referencias a la jurisprudencia de Estrasburgo. Se 
emplearán como términos equivalentes grupos religiosos, Iglesias, comunidades o confesiones religiosas, sin pretender ninguna diferenciación técnicojurídica respecto del uso de unos u otros términos.

\section{RELIGIÓN Y CREENCIAS EN EL DERECHO ORIGINARIO}

Teniendo en cuenta el singular proceso de formación de la Unión Europea, el fenómeno religioso y de creencias pasa por dos perspectivas jurídicas. Podría hablarse, siguiendo un cierto símil constitucional, de una perspectiva orgánica (las relaciones de la UE con las religiones y creencias) y otra dogmática (el reconocimiento y protección del derecho fundamental de pensamiento, de conciencia y de religión). Examinemos cada una de ellas.

\section{UNA PERSPECTIVA JURÍDICA ORGÁNICA}

La perspectiva orgánica queda reflejada en el art. 17 del Tratado de Funcionamiento de la Unión Europea (en adelante TFUE), en el que se indica:

1. La Unión respetará y no prejuzgará el estatuto reconocido en los Estados miembros, en virtud del derecho interno, a las Iglesias y las asociaciones o comunidades religiosas. 2. La Unión respetará asimismo el estatuto reconocido, en virtud del derecho interno, a las organizaciones filosóficas y no confesionales. 3. Reconociendo su identidad y su aportación específica, la Unión mantendrá un diálogo abierto, transparente y regular con dichas iglesias y organizaciones.

Son bien conocidos los orígenes de este artículo, que se remontan a la Declaración 11 del Tratado de Ámsterdam de $1997^{2}$, pasan por el Proyecto de Constitución Europea en su art. I-52 y desembocan en el texto actual. Para algunos autores, el art. 17 es producto de la influencia de las Iglesias cristianas en el proceso constituyente de la Unión Europea, intentando blindar sus privilegios frente al avance de la Unión Europea en la protección de las libertades del individuo (Polo Sabau, 2014: 131-33), obstaculizando «el avance hacia

2 Tratado de Ámsterdam por el que se modifican el Tratado de la Unión Europea, los tratados constitutivos de las Comunidades Europeas y determinados actos conexos, firmado en Ámsterdam el 2 de octubre de 1997, DO C 340/1 de 10 de noviembre de 1997. 
la laicidad común» (Fernández-Coronado González, 2002:123). Para otros sectores, el art. 17 es un límite ante el temor de que en el proceso de constitucionalización de la Unión Europea se impusieran exigencias que hicieran peligrar ese frágil "punto de equilibrio» estructural (Durham, 2006: 53), que son las relaciones entre los Estados y las religiones (Rodrigues Araújo, 2012: 101). No obstante lo anterior, me parece que el art. 17 está articulado en dos elementos. El primero es la neutralidad gnoseológica y deferente de la Unión Europea hacia los Estados en lo que se refiere a sus sistemas de relación con las religiones: la Unión Europea respeta y no prejuzga el sistema per se. Y el segundo elemento es el establecimiento de un cauce de relación entre esas instituciones y la Unión Europea concretado en un «diálogo abierto, transparente y regular» (Barnett, 2005; Leustean, 2016; Lillo, 2018; Pasikowska-Schnass, 2018). Dicho de otro modo: frente a la definición de los Estados europeos como confesionales, aconfesionales, laicos, etc., la Unión Europea, que se está expresando como una entidad política nueva, se sitúa de forma deferencial en este tema y, simultáneamente, reconoce de manera implícita el valor específico de los grupos sociales que encarnan la herencia religiosa y humanista de Europa mencionada en el preámbulo del Tratado de la Unión Europea ${ }^{3}$, haciendo posible a través del diálogo que esa herencia siga inspirando el proyecto europeo e incluso insuflando un alma a Europa (Cerutti y Rudolph, 2001; Hogebrink, 2015; Matlak, 2018). Los grupos religiosos tienen un valor también instrumental como reclamantes y protectores de la libertad de los individuos (Ibán Pérez, 2006: 300). Por lo demás, el art. 17 TFUE se integra con otros dos ejes (Rodrigues Araújo, 2012: 105): el respeto por la identidad de los Estados miembros del art. 4 del Tratado de la Unión Europea y el respeto por la diversidad religiosa del art. 22 de la Carta de Derechos Fundamentales de la Unión Europea (en adelante CDFUE) ${ }^{4}$. El derecho de la Unión Europea, en fin, permitiría afirmar que hay un conjunto normativo (derecho europeo en materia religiosa) caracterizado por siete principios fundamentales (Doe, 2011: 237-257): valoración de la religión, subsidiaridad, neutralidad de la Unión Europea respecto de las relaciones Estado-Iglesias, libertad religiosa, igualdad religiosa, autonomía de los grupos religiosos, cooperación con las

3 «Inspirándose en la herencia cultural, religiosa y humanista de Europa, a partir de la cual se han desarrollado los valores universales de los derechos inviolables e inalienables de la persona, así como la libertad, la democracia, la igualdad y el Estado de Derecho".

4 Carta de Derechos Fundamentales de la Unión Europea, DO C 364/1, 18 de diciembre de 2000. 
religiones, especial protección de la religión en virtud de privilegios y exenciones.

\section{UNA PERSPECTIVA DOGMÁTICA: EL DERECHO FUNDAMENTAL DE LIBERTAD RELIGIOSA}

En segundo lugar, la perspectiva dogmática es la propia del derecho fundamental de libertad de pensamiento, conciencia y religión plasmada en el art. 10 CDFUE:

1. Toda persona tiene derecho a la libertad de pensamiento, de conciencia y de religión. Este derecho implica la libertad de cambiar de religión o de convicciones, así como la libertad de manifestar su religión o sus convicciones individual o colectivamente, en público o en privado, a través del culto, la enseñanza, las prácticas y la observancia de los ritos. 2. Se reconoce el derecho a la objeción de conciencia de acuerdo con las leyes nacionales que regulen su ejercicio.

En las explicaciones sobre la CDFUE redactadas por el Presidium ${ }^{5}$ hay una remisión al art. 9 del Convenio (europeo) para la Protección de los Derechos Humanos y de las Libertades Fundamentales (en adelante CEDH), tanto respecto al contenido del derecho reconocido (primer párrafo) como respecto de las restricciones legítimas que pudiera el poder público establecer al ejercicio del derecho (segundo párrafo). Respecto del reconocimiento del derecho a la objeción de conciencia que se recoge en el art. 10.2 CDFUE, las explicaciones remiten a las tradiciones constitucionales nacionales y a la evolución legislativa en la materia; no obstante, puesto que el TEDH está desarrollando las implicaciones del art. 9 en materia de objeción de conciencia, esta otra vía podría resultar también relevante a los efectos de este derecho fundamental.

En cuanto al alcance e interpretación del derecho fundamental de libertad religiosa, es preciso anotar las singularidades que aporta la historia en las constituciones de los países miembros de la Unión Europea, al tiempo que destacar la ausencia de particulares debates en la redacción del art. 10 CDFUE (Martín y Pérez de Nanclares, 2008: 257-259). La íntima conexión establecida entre el art. 10 CDFUE y el art. $9 \mathrm{CEDH}$ conduce a analizar el primero desde el segundo, y más en concreto desde el despliegue efectuado por el TEDH a

5 Explicaciones sobre la Carta de los Derechos Fundamentales, DO C 303/17, 14 de diciembre de 2007. 
partir del año 1993 con la sentencia Kokkinakis ${ }^{6}$ que marca el comienzo de un significativo número de pronunciamientos judiciales hasta el día de hoy en múltiples materias relacionadas con la libertad religiosa. Y en este sentido, conviene tener presente que, en la interpretación de este derecho fundamental, el TEDH ha distinguido una dimensión interna (forum internum, libertad de elección de religión o creencias) y una dimensión externa (forum externum, libertad de manifestar la propia religión o creencias). La dimensión externa es limitable, conforme a las condiciones del art. 9.2 $\mathrm{CEDH}$, mientras que la dimensión interna de la libertad religiosa es absoluta, no se puede limitar. La libertad de elección significa que toda persona tiene derecho a profesar una religión, abandonarla, cambiar de religión o no tener ninguna. El TEDH entiende que solo se consideran creencias aquellas opiniones que alcanzan un cierto nivel de fuerza, seriedad, coherencia e importancia ${ }^{7}$, algo diferente de lo que el art. $10 \mathrm{CEDH}$ considera como opiniones o ideas, protegidas por la libertad de expresión. La libertad religiosa y de creencias comprende un aspecto negativo, es decir no verse obligado a expresar o revelar, de forma directa o indirecta, las propias creencias, y un aspecto positivo, que consiste en manifestar las creencias conforme a las distintas formas que son descritas en el propio art. 9, que pueden efectuarse en privado o en público, mediante el culto, la enseñanza o la práctica religiosas (Martínez-Torrón, 2016: 174-178).

Pero no solo el art. 10 CDFUE guarda relación con la religión o las creencias; también pueden verse conectados los arts. 9 (derecho a contraer matrimonio y derecho a fundar una familia), 14 (derecho a la educación), 21 (no discriminación) y 22 (diversidad cultural, religiosa y lingüística) (Landete Casas, 2007; Rodrigues Araújo, 2012: 155-167).

Excedería aquí incluso una síntesis acerca del derecho europeo derivado relacionado con la religión y las creencias. No tanto por una creciente regulación o por un aumento de la diversidad religiosa, ya que esta era una realidad presente desde tiempo atrás. Más bien podemos considerar que se produce una conjunción de varios factores, lo que significa que una mayor regulación en apariencia neutral termina incidiendo de forma inopinada en la religión o las creencias. También la igualdad y no discriminación se combinan con el fenómeno religioso de forma particularmente significativa (Sandberg, 2011), confirmando así un previsible aumento de litigiosidad (Martín y Pérez de

6 Sentencia de 25 de mayo de 1993, Kokkinakis v. Greece, CE:ECHR:1993:0525JUD 001430788, sobre la sanción penal del proselitismo religioso.

7 Sentencia de 25 de febrero de 1982, Campbell and Cosans v. the United Kingdom, $\$ 36$, CE:ECHR:1982:0225JUD000751176. 
Nanclares, 2008: 168). Lo cierto es que ha sido en los tres últimos años cuando se ha producido una eclosión de decisiones del TJUE.

\section{LA JURISPRUDENCIA DEL TRIBUNAL DE JUSTICIA DE LA UNIÓN EUROPEA SOBRE RELIGIÓN Y CREENCIAS}

Esa eclosión de decisiones se concentra, por el momento, entre los años 2017 y 2019. En concreto, 4 corresponden a 2017, 6 a 2018 y 3 a 2019. No quiere decir esto que con anterioridad no se hubiera pronunciado la justicia de la actual Unión Europea acerca de temas relativos a la religión o las creencias, y es por ello que este estudio comienza en la década de los años setenta del siglo pasado.

\section{PRIMERAS SENTENCIAS Y DECISIONES CONEXAS}

Nos situamos en 1974. Ivonne van Duyn es ciudadana holandesa y solicita un permiso de entrada en el Reino Unido con el fin de trabajar para la Iglesia de la Cienciología. Las autoridades británicas le niegan el permiso pues consideran peligrosas las actividades de ese grupo religioso. Recurrida la decisión administrativa, la Chancery Division de la High Court of Justice de Inglaterra eleva una cuestión prejudicial sobre el art. 49 del Tratado de la Comunidad Económica Europea (libre circulación de trabajadores) y el art. 3 de la Directiva 64/221/ CEE para la coordinación de las medidas especiales para los extranjeros ${ }^{8}$. Se trata de dilucidar la compatibilidad de la medida adoptada, denegando el permiso, con la libre circulación de trabajadores que preside el derecho comunitario y con la exigencia establecida por la citada directiva de que las restricciones a la libre circulación establecidas por razones de orden público o seguridad pública deben estar motivadas por el comportamiento personal del individuo, cosa que parece que no ocurría en este caso. En su sentencia ${ }^{9}$, el Tribunal de Justicia establece que el art. 48 del Tratado de la Comunidad Económica Europea es de directa aplicación, que la Directiva 64/221/CEE otorga

8 Art. 3. 1. Las medidas de orden público o de seguridad pública deberán estar fundamentadas, exclusivamente, en el comportamiento personal del individuo a que se apliquen. 2. La mera existencia de condenas penales no constituye por sí sola motivo para la adopción de dichas medidas. Directiva 64/221/CEE del Consejo, de 25 de febrero de 1964, para la coordinación de las medidas especiales para extranjeros en materia de desplazamiento y de residencia, justificadas por razones de orden público, seguridad y salud pública (DO 1964, 56, de 25 de febrero de 1964).

9 Sentencia del Tribunal de Justicia de 4 de diciembre de 1974, Van Duyn, EU:C: 1974:133. 
un derecho a los particulares que pueden alegar ante los tribunales de un Estado miembro, que la afiliación a una asociación o grupo puede considerarse como parte de la conducta personal y que, aun cuando dicha asociación no esté prohibida en el país que recibe a un nacional de otro Estado miembro, y aun cuando a los propios nacionales no se les impida trabajar para dicha asociación, sin embargo resulta legítimo restringir, por razones de orden público, la entrada de ciudadanos de otros países europeos que pretendan trabajar para esa asociación.

La decisión podría haberse pronunciado respecto de otro tipo de grupo no religioso, quizá con un resultado semejante. Pero pudo influir en aquellos momentos el clima europeo de desconfianza estructural hacia los nuevos movimientos religiosos (Motilla, 1990: 70-88).

Años más tarde, de nuevo el Tribunal se reencuentra con la Iglesia de la Cienciología en una cuestión relativa a la compatibilidad del régimen de autorización previa para inversiones extranjeras en Francia que pudieran afectar al orden público y a la seguridad pública ${ }^{10}$. En su decisión, el Tribunal de Justicia sostiene la importancia de interpretar de forma estricta los límites de orden público y seguridad pública, al tiempo que determina que el derecho comunitario no permite un régimen de autorización previa en el que las circunstancias específicas limitantes no se encuentren bien definidas.

Un aspecto particular de la libre circulación de personas y servicios es la facultad para ejercer una profesión en un Estado miembro distinto de aquel en que hayan adquirido el título profesional. La Directiva 98/5/CE del Parlamento Europeo y del Consejo establece el marco para facilitar el ejercicio de la profesión de abogado en un país miembro distinto del que otorgó el título ${ }^{11}$. En 2015, Ireneo, un monje ortodoxo griego que había obtenido su título de abogado en Chipre, se dirige al Colegio de Abogados de Grecia para solicitar su inscripción como abogado que ha adquirido esta condición profesional en otro Estado. El Colegio de Abogados deniega la solicitud, pues las disposiciones nacionales establecen la incompatibilidad entre el ejercicio de la abogacía en Grecia y la condición de monje ortodoxo. Ante la negativa, Ireneo recurre al Consejo de Estado y este plantea una cuestión prejudicial acerca de la interpretación del art. 3 de la mencionada directiva. El TJUE efectúa, en Monachos

10 Sentencia del Tribunal de Justicia de 14 de marzo de 2000, Église de scientologie, C-54/99, EU:C:2000:124.

11 Directiva 98/5/CE del Parlamento Europeo y del Consejo de 16 de febrero de 1998 destinada a facilitar el ejercicio permanente de la profesión de abogado en un Estado miembro distinto de aquel en el que se haya obtenido el título (DO L 077, de 14 de marzo de 1998). 
Eirinaios $^{12}$, una interpretación orgánica del art. 3: este artículo dispone que los abogados que deseen ejercer en un Estado miembro distinto de aquel en el que hayan obtenido su título profesional deberán inscribirse ante la autoridad competente de dicho Estado; esta exigencia no queda desvirtuada por el hecho de que el art. 6 de la Directiva someta a los abogados que ejerzan en el Estado miembro de acogida a las mismas normas profesionales y deontológicas que obligan a quienes ejercen con el título profesional del Estado de acogida. Se distingue, por tanto, entre inscripción ante la autoridad competente y ejercicio efectivo conforme a las normas profesionales y deontológicas de Grecia. Lo primero ha sido objeto de armonización completa, lo segundo queda a disposición del legislador nacional que puede establecer requisitos con el fin de, como parece ser en el caso, preservar la independencia del abogado frente a las autoridades, de las que conviene que no reciban influencia alguna (apdos. 18 y 33); «denegar a un abogado que desea ejercer en el Estado miembro de acogida haciendo uso de su título profesional de origen la inscripción ante las autoridades competentes de este Estado miembro por la mera razón de que ostenta la condición de monje equivaldría a añadir un requisito de inscripción» (apdo. 34). En consecuencia, y como conclusión, el art. 3 de la Directiva se opone a que la normativa nacional prohíba a un monje inscribirse ante la autoridad competente del Estado miembro de acogida.

Para quien conoce el estatuto jurídico de los ministros de culto en Grecia, no le extrañará esa prohibición que establece la ley nacional para el ejercicio de la abogacía: el Estado incorpora a su normativa exigencias internas de la religión ortodoxa y su Consejo de Estado es competente para conocer de controversias religiosas (González Sánchez, 2019: 3). ¿En qué medida el Tribunal de Justicia debería haber atendido al art. 17 TFUE, para curvar una excepción, a la vista de la peculiar normativa griega? En ninguna, pues la decisión tan solo exige el cumplimiento del derecho de la Unión, que no se extiende más allá de la inscripción, sin entrar en el ejercicio.

Pero volvamos a la década de los setenta del siglo pasado. En 1976 llegó la decisión que durante largo tiempo ha sido punto de referencia acerca de la colisión de las creencias religiosas con el calendario laboral o lectivo, lo que desde otra perspectiva se designa objeción de conciencia al calendario laboral $^{13}$. Vivien Prais es una ciudadana británica de religión judía que presenta

12 Sentencia del Tribunal de Justicia (Gran Sala) de 7 de mayo de 2019, Monachos Eirinaios, C-431/17, EU:C:2019:368.

13 Véase, por ejemplo, Sentencia del Tribunal Supremo 3533/2015, de 6 de julio de 2015, ES:TS:2015:3533, sobre el derecho de la opositora miembro de la Iglesia Adventista del Séptimo, aspirante al Cuerpo de Maestros, a la celebración de un examen 
su solicitud para participar en el examen para traductora de inglés en las Comunidades Europeas. Admitida para tomar parte en las pruebas, se le comunica que los exámenes escritos tendrán lugar el 16 de mayo de 1975; a su vez, Prais comunica el 25 de abril que el 16 de mayo comienza la fiesta de Shavuot y no podrá por motivos religiosos realizar las pruebas escritas, solicitando que se le ofrezca una fecha alternativa, a lo cual el Consejo de las Comunidades contesta que no es posible ya que los candidatos deben examinarse de forma simultánea en Londres y Bruselas. El 14 de julio de 1975 Prais presenta una queja, que es rechazada, y en diciembre presenta su demanda al Tribunal de Justicia. El fallo de la sentencia es bien conocido por todos: si una oposición se efectúa a partir de unos exámenes, el principio de igualdad exige que estos se desarrollen en las mismas condiciones para todos los candidatos, lo cual comprende la misma fecha. Si un aspirante informara a tiempo a la autoridad convocante de sus reparos, esta circunstancia debe ser tenida en cuenta; si ese aspirante no informa con la debida antelación, la autoridad convocante puede legítimamente negarse a ofrecer una fecha alternativa. Puesto que, en este caso, la candidata no informó con suficiente antelación, la autoridad no queda obligada a ofrecer otra fecha. Detrás del resultado final, en Prais encontramos tres elementos relevantes. Primero: la libertad religiosa tiene un alcance mayor que el de impedir creer o no creer; en el caso concreto, el Consejo no ha impedido a la candidata creer y practicar el judaísmo y, sin embargo, la libertad religiosa parece amparar algo más. Segundo, unido a lo anterior, el reconocimiento de la libertad religiosa comprende una obligación positiva de la autoridad pública que, si conoce los obstáculos de la candidata, debe tomar las medidas razonables («reasonable steps») para evitar una convocatoria en fechas inhábiles para la opositora. Y tercero: esa obligación positiva nos sitúa a las puertas de poder afirmar que existe un deber de acomodación razonable (Bribosia, Ringelheim y Rorive, 2010: 158; Castro Jover, 2011: 103). Por acomodación razonable se entiende toda modificación o ajuste en un empleo que permita a un potencial trabajador (por lo demás cualificado) o a un empleado, normalmente de origen cultural o religioso diferente del de la mayoría de la población, participar en el proceso de selección o desempeñar los cometidos esenciales del empleo de forma igual que el resto de los candidatos o empleados, pero respetándose sus convicciones (Relaño Pastor, 2016: 256).

en día alternativo. Ante el Tribunal Europeo de Derechos Humanos, Francesco Sessa v. Italy, 28790/08, ECHR 2012, CE:ECHR:2012:0403JUD002879008. 


\section{DERECHO EUROPEO Y ACTIVIDAD ECONÓMICA DE GRUPOS RELIGIOSOS}

En 1988 una aislada decisión prejudicial plantea la actividad profesional al servicio de un nuevo movimiento religioso. En concreto, Udo Steymann, de nacionalidad alemana y residente en los Países Bajos, se hizo miembro de un grupo religioso denominado "comunidad Bhagwan», realizando arreglos de fontanería, trabajos domésticos en el inmueble de dicha comunidad y colaborando en la actividad económica del grupo, que lleva la explotación de una discoteca, un establecimiento de bebidas y una lavandería automática. La comunidad religiosa, por su parte, atiende a las necesidades económicas de Steymann. El 28 de agosto de 1984, Steymann pidió permiso de residencia en los Países Bajos, que le fue denegado por las autoridades nacionales al considerar que no ejercía una actividad asalariada. Steymann recurre la resolución administrativa a la justicia holandesa, que plantea su recurso sobre la base de los arts. 59 y 60 del Tratado de Roma que regulan la libre prestación de servicios. Se trata de dilucidar si las labores que desempeña Steymann constituyen prestación de servicios a los efectos del permiso de residencia ${ }^{14}$. El tribunal comienza situándose, y esto resulta relevante, en una posición de deferencia hacia los grupos religiosos cuando afirma: "[...] teniendo en cuenta los objetivos de la Comunidad, la participación en una comunidad, basada en la religión o en otra fuente de inspiración espiritual o filosófica, solo está comprendida en el ámbito de aplicación del Derecho comunitario en la medida en que pueda considerarse como una actividad económica en el sentido del art. 2 del Tratado» (apdo. 9). El tribunal entiende que de los trabajos realizados en nombre y por cuenta del citado grupo religioso en el ejercicio de sus actividades comerciales, y de la manutención y dinero de bolsillo que reciben los fieles (con independencia de la naturaleza y extensión de los trabajos), no puede excluirse a priori que los trabajos de los fieles sean actividad económica. Pero debe tratarse de trabajos reales y efectivos, no marginales y accesorios. Ahora bien, conforme a la dicción del art. 60 del Tratado, una actividad permanente o ejercida sin límite previsible de duración no puede estar comprendida en el ámbito de las disposiciones comunitarias relativas a las prestaciones de servicios. El tribunal, en definitiva, no impone una calificación jurídica sobre la actividad laboral o no laboral de los miembros de un grupo religioso, pero sí se pronuncia sobre su carácter de actividad económica, y en este sentido cabe entender que no prejuzga la calificación y el tratamiento jurídico que los

14 Sentencia del Tribunal de Justicia de 5 de octubre de 1988, Steymann, C-196/87, EU:C:1988:475. 
ordenamientos estatales otorgan a, por ejemplo, las actividades que los ministros de culto realizan al servicio de su propia Iglesia o comunidad.

Damos un salto en el tiempo para situarnos en el año 2017. Una congregación religiosa católica dedicada a la educación efectuó unas obras de reforma y ampliación del edificio de salón de actos de un colegio para las que solicitó licencia y pagó al Ayuntamiento de Getafe 23730,41 euros por el Impuesto de Construcciones, Instalaciones y Obras. Posteriormente, solicita la devolución de esa cantidad, entendiendo que estaba exenta del pago del impuesto en virtud del Acuerdo sobre asuntos económicos entre España y la Santa Sede de 1979 y de la normativa fiscal española. Rechazada su solicitud por el Ayuntamiento de Getafe, plantea la congregación religiosa un recurso ante el Juzgado de lo Contencioso-Administrativo núm. 4 de Madrid ${ }^{15}$. Este plantea un recurso relativo a la interpretación del art. 107 TFUE $^{16}$ : ¿constituye la exención del Impuesto de Construcciones, Instalaciones y Obras una encubierta ayuda otorgada por el Estado que falsea la competencia, favoreciendo a un empresario educativo, en este caso una congregación religiosa? Con el fin de determinar si es aplicable el art. 107, el Tribunal de Justicia se pregunta si la congregación religiosa puede calificarse como empresa y si realiza una actividad económica, respondiendo afirmativamente. Respecto de la actividad económica, el tribunal distingue la enseñanza concertada y la no concertada, a los efectos de excluir la primera del carácter económico de la actividad. Y puesto que en un mismo centro de enseñanza se desarrollan actividades económicas y no económicas, sería posible distinguir ambas «siempre que mantenga una contabilidad separada por lo que respecta a la diferente financiación recibida, de modo que se excluya todo riesgo de subvención "cruzada" de sus actividades económicas mediante fondos públicos de los que se beneficia en relación con sus actividades no económicas» (apdo. 51), añadiendo que «siempre y cuando el órgano jurisdiccional remitente considere, en virtud de una apreciación de los hechos, que el salón de actos se destina a actividades realizadas por la Congregación que hayan de calificarse de "económicas", deberá examinarse a continuación si, en una situación como la que es objeto del litigio principal, se cumplen los cuatro requisitos señalados en el apdo.

15 Sentencia del Tribunal de Justicia (Gran Sala) de 27 de junio de 2017, Congregación de Escuelas Pías Provincia Betania, C-74/16, EU:C:2017:496.

16 Art. 107 (antiguo art. 87 TCE) 1. Salvo que los tratados dispongan otra cosa, serán incompatibles con el mercado interior, en la medida en que afecten a los intercambios comerciales entre Estados miembros, las ayudas otorgadas por los Estados o mediante fondos estatales, bajo cualquier forma, que falseen o amenacen falsear la competencia, favoreciendo a determinadas empresas o producciones. 
38 de la presente sentencia» (apdo. 64), requisitos que son en definitiva los contenidos en el art. 107. Más en concreto, para determinar si la ayuda falsea o amenaza con falsear la competencia, el tribunal acude a un criterio estandarizado, excluyendo la ayuda que no supere los 200000 euros en un periodo de tres años, correspondiendo al órgano jurisdiccional remitente determinar si se ha llegado a ese umbral, concluyendo que «una exención fiscal como la controvertida en el litigio principal, de la cual se beneficia una congregación de la Iglesia Católica por las obras realizadas en un inmueble destinado al ejercicio de actividades sin una finalidad estrictamente religiosa, puede estar comprendida en el ámbito de la prohibición establecida en el art. 107 TFUE» (apdo. 90). Al final, como es sabido, el problema para la justicia española fue que la congregación no aportó la contabilidad de los tres últimos años que permitiera distinguir la índole de las actividades y comprobar que no se producía subvención cruzada ${ }^{17}$.

El caso Congregación de Escuelas Pías Provincia de Betania recuerda la existencia histórica de fricciones entre las obligaciones de España con la Unión Europea y las exenciones fiscales concedidas a la Iglesia católica, y más en concreto respecto del IVA (Félix Ballesta y Martínez Félix, 2007; Meseguer Velasco, 2019: 62-66) y que se resolvieron mediante una renegociación entre España y la Santa Sede plasmada en el intercambio de notas entre la Nunciatura española y el Ministerio de Asuntos Exteriores de 22 de diciembre de 2006. En cualquier caso, de fondo hay un disenso permanente en torno al concepto de «fines religiosos» en un contexto en el que actividades sanitarias y educativas son desarrolladas por las confesiones religiosas con una clara vocación o aspiración religiosa amparada por el derecho fundamental de libertad religiosa (Aznar García, 2017: 9). Por otro lado, se ha advertido que este tipo de exenciones que guardan relación con actividades económicas y no religiosas no sería congruente con la promoción de la libertad religiosa, fundamento de la colaboración económica del Estado con los grupos religiosos (Cebriá García, 2017: 20).

\section{RELIGIÓN Y NO DISCRIMINACIÓN}

La parte más significativa de las sentencias del TJUE ha versado sobre la discriminación por motivos religiosos en el ámbito laboral (Vickers, 2008) precisando la interpretación de la Directiva 2000/78/CE del Consejo, de 27

17 Sentencia 1/2018 del Juzgado de lo Contencioso-Administrativo núm. 4 de Madrid de 8 de enero de 2018, ES:JCA:2018:1. 
de noviembre de 2000, relativa al establecimiento de un marco general para la igualdad de trato en el empleo y la ocupación ${ }^{18}$.

Los casos sometidos al tribunal son de tres tipos: discriminación de empleados por uso de simbología o vestimenta religiosa (G4S Secure Solutions y Bougnaoui y $A D D H$ ), discriminación de empleados por parte de las confesiones religiosas (IR y Egenberger) y discriminación por motivos religiosos de empleados en virtud de normas estatales (Cresco Investigation). Estudiemos cada tipo por separado.

\subsection{Discriminación y símbolos o vestuario religioso}

Los debates jurídicos en torno al vestuario o la simbología religiosa constituyen un sector de estudio consolidado en el que el TEDH ha tenido un importante papel protagonista ${ }^{19}$. Con las dos sentencias que estudiamos a continuación, el TJUE se enfrenta a esta cuestión desde la perspectiva de la discriminación en el empleo.

Samira Achbita, musulmana, trabaja como recepcionista para una empresa belga de servicios con un contrato de trabajo indefinido. En la empresa existe una norma no escrita conforme a la cual los trabajadores no podían llevar signos visibles de sus convicciones políticas, filosóficas o religiosas en el lugar de trabajo. Inicialmente Achbita cumple con esta norma, pero a los tres años de iniciada la relación laboral comunica su intención de trabajar con pañuelo a la cabeza. La dirección indica que no toleraría tal conducta. El 29 de mayo de 2006 el comité de empresa aprobó una modificación del reglamento interno que incorpora la norma no escrita acerca de la prohibición de signos visibles. La modificación entró en vigor el 13 de junio de 2006. El 12 de junio Achbita fue despedida. Recurrido el despido por la trabajadora, la cuestión llega hasta el Tribunal de Casación de Bélgica, quien plantea al TJUE una cuestión prejudicial

18 Directiva 2000/78/CE del Consejo, de 27 de noviembre de 2000, relativa al establecimiento de un marco general para la igualdad de trato en el empleo y la ocupación (DO L 303, de 2 de diciembre de 2000).

19 Justificando la restricción del uso de símbolos religiosos, entre otras, las sentencias del TEDH de 1 de julio de 2014 S.A.S. v. France [GC], CE:ECHR:2014:0701JUD004383511, y de 10 de noviembre de 2005, Leyla Şahin v. Turkey [GC], 44774/98, CE:ECHR:2005:1110JUD004477498. Declarando la restricción contraria a la libertad religiosa, la Sentencia de 23 de febrero de 2010, Ahmet Arslan and Others v. Turkey, CE:ECHR:2010:0223JUD004113598, y de 15 de enero de 2013, Eweida and Others v. the United Kingdom, CE:ECHR:2013:0115JUD004842010. 
en estos términos ${ }^{20}$ : «iDebe interpretarse el art. 2, apdo. 2, letra a), de la Directiva 2000/78 en el sentido de que la prohibición de llevar un pañuelo como musulmana en el lugar de trabajo no constituye una discriminación directa, si la norma en vigor en la empresa prohíbe a todos los trabajadores llevar en el lugar de trabajo signos externos de convicciones políticas, filosóficas o religiosas?». El punto de partida es determinar el concepto de religión subyacente a la Directiva por la que se regula la discriminación directa; el tribunal en realidad no llega a determinar dicho concepto, porque aun cuando se remonta al sistema del $\mathrm{CEDH}$ parece confundir el concepto o noción legal de religión (del que solo afirma que es recogido en la CDFUE con una acepción «amplia» del apdo. 28). Sencillamente constata que el derecho fundamental de libertad religiosa contempla dos dimensiones: el forum internum y el forum externum, lo cual apunta a lo que se protege, pero no a lo que la religión es. En cualquier caso, el tribunal señala que la norma controvertida afecta indistintamente a signos visibles de convicciones religiosas, políticas o filosóficas, por lo que no es posible estimar una discriminación directa por motivos religiosos. No obstante, apunta a la posibilidad de que se produjera discriminación indirecta, lo cual deberá valorar el tribunal belga, atendiendo también a lo indicado en el art. 2.2.b) de la propia directiva, es decir, que:

[...] existirá discriminación indirecta cuando una disposición, criterio o práctica aparentemente neutros pueda ocasionar una desventaja particular a personas con una religión o convicción, con una discapacidad, de una edad, o con una orientación sexual determinadas, respecto de otras personas, salvo que: i) dicha disposición, criterio o práctica pueda justificarse objetivamente con una finalidad legítima y salvo que los medios para la consecución de esta finalidad sean adecuados y necesarios.

En principio, el tribunal estima que hay una finalidad legítima (el deseo de un empresario de ofrecer una imagen neutra ante sus clientes), que la medida es adecuada (es apta para garantizar la correcta aplicación de un régimen de neutralidad, siempre que dicho régimen se persiga realmente de forma congruente y sistemática) y que también podría tratarse de una medida necesaria (para lo cual ha de comprobarse si la prohibición del uso visible de cualquier signo o prenda de vestir que pueda asociarse a una creencia religiosa o a una convicción política o filosófica atañe únicamente a los trabajadores de G4S que están en contacto con los clientes). En conclusión, el tribunal estima que no hay discriminación directa conforme a la directiva, pero sí podría haber

20 Sentencia del Tribunal de Justicia (Gran Sala) de 14 de marzo de 2017, G4S Secure Solutions, C-157/15, EU:C:2017:203. 
discriminación indirecta, asunto que puede estudiar, en su caso, el tribunal belga.

El aspecto que resulta más chocante en la sentencia es la legitimidad que se otorga a la neutralidad de empresa. En general, como principio que el poder público debe respetar, la neutralidad se presenta como una obligación instrumental del Estado (y de los poderes públicos en general, también de la Unión Europea) para la cabal protección de la libertad religiosa y de creencias. La neutralidad en el ámbito de la libertad de empresa podría ser un principio dirigido a garantizar la igual oferta de bienes y servicios, así como la igualdad de trato de los empleados. Pero la neutralidad no aparece como uno de los elementos que hacen legítima la restricción del disfrute de la libertad religiosa conforme al CEDH (Howard, 2007: 66). El principio de neutralidad como parte del ideario de la empresa podría constituir la coartada jurídica perfecta para otorgar carta de naturaleza al prejuicio (Giles, 2018: 344; Pavlidou, 2018: 159). Cabría esperar una valoración mucho más detallada de los motivos o fundamentos de la política empresarial de neutralidad (Relaño Pastor, 2016: 267). Para el TJUE la neutralidad religiosa de la empresa es predicable de una norma que prohíbe todo tipo de símbolos en los trabajadores, sea del tipo que sean, sin indagar en su conexión más o menos intensa con las creencias (Weiler, 2018). Esta postura no parece que sea de neutralidad hacia la religión, sino de exclusión del hecho religioso; «es como si una política de neutralidad en materia de discapacidad conllevara que la empresa adoptara la decisión de no contratar a personas con algún tipo de discapacidad reconocida para respetar los diversos tipos de discapacidad y no discriminar así entre las discapacidades físicas, las psíquicas o las sensoriales. La neutralidad conllevaría así la exclusión de trabajadores con diversidad funcional» (Rodríguez Blanco, 2017: 389).

En la misma fecha, el TJUE resolvió la cuestión prejudicial planteada por un tribunal de Francia, también relativa a la Directiva 2000/78, cuyo supuesto es el siguiente ${ }^{21}$ : Asma Bougnaoui, de religión islámica, trabaja en la empresa Micropole. Tanto en el periodo de prácticas como posteriormente, la empresa Micropole advirtió a Bougnaoui que no debía vestir velo islámico en el trabajo, indicación que no acató. Micropole despide a su empleada el 22 de junio de 2009, después de que una de sus empresas clientes le hiciera saber que a algunos de sus empleados les había molestado que Asma Bougnaoui llevara velo; el cliente pidió que "no hubiera velo la próxima vez». Bougnaoui demanda a la empresa ante los tribunales laborales. Y tras su recurso a la Corte

21 Sentencia del Tribunal de Justicia (Gran Sala) de 14 de marzo de 2017, Bougnaoui y $A D D H, \mathrm{C}-188 / 15$, EU:C:2017:204. 
de Casación, esta plantea la cuestión prejudicial respecto de la normativa de trasposición de la mencionada directiva: «¿Debe interpretarse el art. 4, apdo. 1, de la Directiva 2000/78 22 en el sentido de que el deseo manifestado por un cliente de una empresa de consultoría informática de que, en lo sucesivo, los servicios informáticos contratados no sean prestados por una asalariada de dicha empresa, ingeniero de proyectos, que usa un pañuelo islámico constituye un requisito profesional esencial y determinante, debido a la naturaleza de la actividad profesional concreta de que se trata o al contexto en que se lleva a cabo?». Obsérvese que la pregunta que formula la Corte de Casación no agota todo el escenario relevante a efectos de discriminación, en el sentido de que la empresa ya había manifestado a la empleada que no quería que acudiera al trabajo portando el velo islámico. El análisis del caso por parte del tribunal se centra en determinar si estamos ante un requisito profesional esencial y determinante, y si el objetivo del requisito es legítimo y proporcionado; el TJUE llega a conclusión de que «el concepto de "requisito profesional esencial y determinante", en el sentido de esta disposición, implica un requisito objetivamente dictado por la naturaleza de la actividad profesional de que se trate o por el contexto en que esta se lleve a cabo. En cambio, no puede cubrir consideraciones subjetivas, como la voluntad del empresario de tener en cuenta los deseos particulares del cliente» (apdo. 40). Ni el velo forma parte de la actividad de una ingeniera de proyectos, ni los deseos del cliente forman parte del desempeño de la tarea profesional.

Las dos sentencias, por su coincidencia cronológica y temática, han sido estudiadas de forma conjunta por la doctrina académica. Además, las sentencias y decisiones del TEDH sobre simbología religiosa permitían establecer una comparación entre estas dos sentencias y las del TEDH, aventurando la posibilidad de un "forum shopping» de los europeos para lograr una mejor protección de sus derechos (Fokas, 2016: 544). En general, ambas sentencias han sido acogidas de forma crítica: G4S Secure Solutions y Bougnaoui parecen dar carta de naturaleza a una contradicción interna. Por un lado, los Estados y las empresas europeas no se oponen a que la gente exprese sus creencias religiosas, pero, por otro, reclaman de forma creciente a los individuos que

22 Art. 4. Requisitos profesionales 1 . No obstante lo dispuesto en los apdos. 1 y 2 del art. 2, los Estados miembros podrán disponer que una diferencia de trato basada en una característica relacionada con cualquiera de los motivos mencionados en el art. 1 no tendrá carácter discriminatorio cuando, debido a la naturaleza de la actividad profesional concreta de que se trate o al contexto en que se lleve a cabo, dicha característica constituya un requisito profesional esencial y determinante, siempre y cuando el objetivo sea legítimo, y el requisito, proporcionado. 
restrinjan su libertad a la iglesia y a sus hogares (Baldi, 2018: 311). Ha sido igualmente frecuente, al analizar ambas sentencias, ahondar en las conclusiones de las abogadas generales, para afirmar, entiendo que de manera fundada, que hay contradicciones (Leal Adorna, 2018; Nuevo López, 2017; Pavlidou, 2018; Pelayo Olmedo, 2017). Contradicciones ya desde el punto de partida, pues para Kokott en G4S Secure Solutions la religión es una opción personal, de menor fuerza que factores como el sexo, la lengua, la etnia, etc. ${ }^{23} \mathrm{y}$ para Sharpston en Bougnaoui es un factor de identidad esencial de la persona ${ }^{24}$.

Por último, se plantea también si tras ambas sentencias queda o no espacio para la acomodación razonable en los casos de discriminación por motivos religiosos. Las opiniones se inclinan a descartar esta posibilidad en atención al hecho de que la acomodación razonable aparece en la Directiva 2000/78 solo para la discapacidad, y subrayando que el nivel de protección de la discriminación religiosa es inferior al otorgado en Estados Unidos y en Canadá

23 «Sin embargo, a diferencia del sexo, el color de la piel, el origen étnico, la orientación sexual, la edad y la discapacidad de una persona, la práctica religiosa no es tanto una circunstancia invariable como un aspecto de la vida privada, en el cual además pueden influir voluntariamente los trabajadores afectados. Mientras que un trabajador no puede "dejar en el guardarropa" su sexo, su color de piel, su origen étnico, su orientación sexual, su edad ni su discapacidad al acceder a las instalaciones de su empresario, sí se le puede exigir un cierto recato en el trabajo con respecto al ejercicio de su religión, ya sea en relación con sus prácticas religiosas, sus comportamientos motivados por la religión o (como aquí sucede) su forma de vestir» (Conclusiones de la abogado general Kokott de 31 de mayo de 2016, C-157/15, G4S Secure Solutions, EU:C:2016:382, punto 116).

24 "Cuando un empresario firma un contrato de trabajo con un trabajador, no compra el alma de esta persona. Sin embargo, sí compra su tiempo. Por esta razón, hago una clara distinción entre la libertad de una persona de manifestar su religión —cuyo alcance y posible limitación en el ámbito laboral constituyen el objeto principal del procedimiento ante el juez nacional- y el hecho de hacer proselitismo de su religión. Como demostraré a continuación, conciliar la libertad de una persona de manifestar su religión con la libertad de empresa requerirá un difícil ejercicio de equilibrio entre dos derechos en conflicto. A mi modo de ver, el proselitismo simplemente no tiene lugar en el ámbito laboral. El empresario está por lo tanto legitimado a imponer y poner en práctica reglas que prohíben el proselitismo, tanto para asegurarse de que el tiempo por el que ha pagado se emplee para su negocio como para crear unas condiciones de trabajo armoniosas para su personal. (75) Dejaré claro que considero que el uso de vestimenta religiosa en el marco de la práctica religiosa pertenece totalmente a la primera categoría, y no a la segunda» (Conclusiones de la abogada general Sharpston presentadas el 13 de julio de 2016, Bougnaoui y $A D D H, \mathrm{C}-188 / 15$, EU:C:2016:553, punto 73). 
(Cañamares Arribas, 2017: 59, 62). Otros sectores entienden que la acomodación razonable está implícita en ambas sentencias (Contreras Mazarío, 2017: 605). Para otros, en fin, no es necesario en el futuro regular la adaptación razonable por motivos religiosos porque la prohibición de la discriminación indirecta resulta suficiente (Stein, 2014).

\subsection{Discriminación de empleados por parte de las confesiones religiosas}

En 2018, el TJUE emite dos sentencias relativas a la interpretación del art. 4.2 de la Directiva 2000/78 que establece una excepción a las normas sobre discriminación en el empleo al servicio de los grupos religiosos y organizaciones de tendencia, permitiendo «una diferencia de trato basada en la religión o las convicciones de una persona cuando, por la naturaleza de estas actividades o el contexto en el que se desarrollen, dicha característica constituya un requisito profesional esencial, legítimo y justificado respecto de la ética de la organización ${ }^{25}$. Con esto se respeta la autonomía de las confesiones religiosas, es decir, el derecho «a promulgar su propio ordenamiento jurídico confesional, y a utilizarlo para autogobernarse y dirimir sus disputas internas» (Celador Angón, 2011: 240). La autonomía de las confesiones se refiere fundamentalmente a la actividad interna de la confesión religiosa distinta de las actividades laborales relacionadas con las confesiones religiosas (Castro Jover, 2011: 106), en las que, sin embargo, hay una «zona de tonos grises» en la que las relaciones laborales pueden estar muy influidas por el ethos religioso.

Vera Egenberger solicitó un puesto de trabajo ofertado por la Evangelisches Werk cuyo contenido era un proyecto de redacción del informe paralelo sobre el Convenio Internacional de las Naciones Unidas relativo a la eliminación

25 Art. 4. Requisitos profesionales [...] 2. Los Estados miembros podrán mantener en su legislación nacional vigente el día de adopción de la presente directiva, o establecer en una legislación futura que incorpore prácticas nacionales existentes el día de adopción de la presente directiva, disposiciones en virtud de las cuales en el caso de las actividades profesionales de iglesias y de otras organizaciones públicas o privadas cuya ética se base en la religión o las convicciones de una persona, por lo que respecta a las actividades profesionales de estas organizaciones, no constituya discriminación una diferencia de trato basada en la religión o las convicciones de una persona cuando, por la naturaleza de estas actividades o el contexto en el que se desarrollen, dicha característica constituya un requisito profesional esencial, legítimo y justificado respecto de la ética de la organización. Esta diferencia de trato se ejercerá respetando las disposiciones y principios constitucionales de los Estados miembros, así como los principios generales del derecho comunitario, y no podrá justificar una discriminación basada en otro motivo. 
de todas las formas de discriminación racial. Respecto de los requisitos que debían cumplir los candidatos, la oferta especificaba que deberían pertenecer a una Iglesia protestante o integrada en la comunidad de trabajo de las Iglesias cristianas de Alemania, debiéndose indicar la confesión cristiana de pertenencia en el curriculum vitae de la solicitud. Vera Egenberger envió su solicitud, pasó la primera selección, pero no fue convocada a la entrevista. El puesto fue obtenido por otro candidato. Egenberger presenta una demanda ante los tribunales alemanes laborales alegando que la toma en consideración de la religión para el puesto de trabajo era discriminatoria. Los tribunales alemanes, por su parte, tenían presente que el art. 9 de la Ley alemana de Igualdad de Trato (que trasponía la Directiva 2000/78) admitía una desigualdad en el empleo ofrecido por grupos religiosos o entidades vinculadas cuando, con arreglo a la propia conciencia de dichas comunidades o entidades, una determinada religión o convicción constituyera un requisito profesional justificado, en atención a su derecho de autonomía o a la naturaleza de sus actividades, lo cual evidentemente deja un amplio margen a la configuración de los empleos. El caso llega hasta el Tribunal Supremo de lo Laboral, que plantea las cuestiones prejudiciales ${ }^{26}$ como una contraposición entre ese art. 9 de la ley alemana y el art. 4.2 de la mencionada directiva: ¿debe interpretarse el art. 4, apdo. 2, de la directiva en el sentido de que una Iglesia o asociación religiosa empleadora puede establecer que la religión del candidato constituye un requisito profesional esencial, legítimo y justificado respecto de su ética? En caso de respuesta negativa a la cuestión, ¿deberá dejarse inaplicado el art. 9, apdo. 1 de la Ley de Igualdad de Trato alemana? ¿Qué requisitos han de cumplir la naturaleza de las actividades o el contexto en el que estas se desarrollan como requisito profesional esencial, legítimo y justificado respecto de la ética de la organización conforme al art. 4, apdo. 2, de la directiva?

Bien podría pensarse que para orientar la respuesta había ya una serie de casos consolidados en la jurisprudencia del TEDH que podían ayudar al $\mathrm{TJUE}^{27}$. Sin embargo, este último advierte que el supuesto se separa de la

26 Sentencia del Tribunal de Justicia (Gran Sala) de 17 de abril de 2018, Egenberger, C-414/16, EU:C:2018:257.

27 Por ejemplo, sentencia del TEDH de 12 de junio de 2014, Fernández Martínez v. Spain [GC], CE:ECHR:2014:0612JUD005603007 (sobre la no renovación de permiso de la autoridad religiosa para contratación como profesor de religión en colegio público); de 20 de octubre de 2010, Lombardi Vallauri c. Italie, CE:ECHR:2009:1020JUD003912805 (despido de profesor de universidad confesional por diferencias con la doctrina religiosa), y de 14 de septiembre de 2017, Károly Nagy v. Hungary [GC], CE:ECHR:2017:0914JUD005666509 (reclamación de remuneración debida a un ministro de culto). 
experiencia previa, pues aquí se trata de una relación laboral aun no existente. Lo que existe es solo un proceso de selección que queda, por supuesto, comprendido en el ámbito de aplicación de la directiva en virtud del art. 3. El TJUE constata que el art. 4.2 de la Directiva tiene por finalidad conjugar el derecho de autonomía de las confesiones religiosas con el derecho de los trabajadores a no ser discriminados. El art. 4 sienta las condiciones de compatibilidad que, en caso de conflicto, deben ser controladas por los tribunales sin que el art. 17 TFUE pueda dispensar de dicho control (Polo Sabau, 2018: 300-304). En consecuencia, la decisión de la Iglesia u organización vinculada de establecer la confesión religiosa como requisito profesional esencial, legítimo y justificado no queda eximida de revisión. Ahora bien, ¿̨con arreglo a qué criterios ha de comprobarse que la religión o las creencias son un requisito profesional esencial, legítimo y justificado? Absteniéndose en todo momento de valorar la legitimidad de la propia ética de la Iglesia o de la organización de que se trate, "la legalidad de una diferencia de trato basada en la religión o las convicciones se supedita a la existencia comprobable objetivamente de un vínculo directo entre el requisito profesional impuesto por el empresario y la actividad de que se trate» (apdo. 63). Ese vínculo directo deriva o bien de la naturaleza de la actividad (predicación, misión, divulgación del credo con la palabra y/o con el ejemplo de vida) o bien de las circunstancias en que debe desarrollarse dicha actividad (representación pública de la confesión religiosa, portavocía... $)^{28}$ y el tribunal identifica cuál es el significado de los términos de requisito profesional «esencial, legítimo y justificado», sin concluir (corresponde al tribunal requirente) si estamos en este caso ante ese tipo de requisito. Respecto de la aplicabilidad o no del art. 9 de la ley alemana, al final el tribunal es claro: «[...] el tribunal nacional está obligado a garantizar, de acuerdo con sus competencias, la protección jurídica para los justiciables derivada de lo dispuesto en los arts. 21 y 47 de la Carta, y a garantizar la plena eficacia de dichos artículos, dejando sin aplicar, en caso necesario, cualquier norma nacional que los contradiga».

Cinco meses después el tribunal se pronuncia de nuevo a solicitud también de la justicia alemana, añadiendo nuevos criterios sobre la interpretación de la Directiva 2000/78 en su art. 4.229. IR es una sociedad de inspiración católica

28 Como en el caso del Tribunal de Estrasburgo en su Sentencia de 23 de septiembre de 2010, Obst v. Germany, CE:ECHR:2010:0923JUD000042503 (sobre el despido del director para Europa en el departamento de relaciones públicas de la Iglesia mormona por conducta moral contraria a los principios de la confesión religiosa).

29 Sentencia del Tribunal de Justicia (Gran Sala) de 11 de septiembre de 2018, IR, C-68/17, EU:C:2018:696. 
que se dedica a la gestión de hospitales y que depende del arzobispado de Colonia. En uno de los hospitales de dicha sociedad trabaja J.Q. como jefe de servicio de medicina interna con un contrato de trabajo basado en el «Reglamento del Servicio Eclesiástico», que impone deberes cualificados tanto para los trabajadores católicos como no católicos, aunque diferentes para unos y otros. En concreto, respecto de los católicos se establece como infracción del deber de lealtad que puede motivar el despido laboral si el trabajador ostenta responsabilidades directivas, la celebración de matrimonio nulo "conforme a la fe y al ordenamiento jurídico de la Iglesia " ${ }^{30} \mathrm{~J}$.Q. es católico y celebró matrimonio civil tras el divorcio de su primer matrimonio canónico, sin haber obtenido la nulidad canónica de este. La empresa procede a despedir a J.Q., quien presenta demanda ante la justicia alemana alegando que el despido vulneraba la igualdad de trato respecto de empleados cristianos no católicos, pues estos no habrían sido despedidos conforme a la norma aplicada en caso de haber seguido una conducta como la suya. Tras una larga peripecia judicial, el Tribunal Supremo de lo Laboral plantea una cuestión prejudicial acerca de la interpretación, otra vez, del art. 9 de la Ley de Igualdad de Trato: ¿es compatible con el art. 4.2 de la Directiva 2000/78 que una confesión religiosa distinga entre trabajadores con responsabilidades directivas católicos y no católicos? ¿Cómo entender a la luz de dicho artículo la «lealtad y buena fe» de los trabajadores hacia la ética de la organización? ¿Debe excluirse de aplicación el art. 9 de la Ley de Igualdad de Trato alemana (que ofrece una intensa protección a la normativa de las confesiones religiosas)?

Obsérvese que la base de la cuestión prejudicial es la igualdad y no discriminación versus la protección normativa nacional y europea de la autonomía de las confesiones religiosas. Es importante tener en cuenta este dato, en caso de intentar comparar las dos sentencias del TJUE con las pronunciadas en situaciones semejantes por el TEDH. Este último ha conocido un buen número de casos, pero normalmente a partir de la alegación por el trabajador

30 Art. 5 del Reglamento del Servicio Eclesiástico de 1993. «Infracciones del deber de lealtad» (1) Si un trabajador deja de cumplir los requisitos de empleo, el empresario deberá intentar, a través del consejo, que el trabajador corrija definitivamente esa irregularidad. [...] Como última medida, podrá considerarse el despido. (2) En especial, la Iglesia considera motivos de despido específicamente eclesiásticos las siguientes infracciones graves del deber de lealtad: [...] — la celebración de un matrimonio nulo conforme a la fe y al ordenamiento jurídico de la Iglesia [...] (3) Cuando sea cometido por [trabajadores] que ejerzan responsabilidades directivas [...], todo comportamiento que, de conformidad con lo dispuesto en el apdo. 2, pueda considerarse con carácter general motivo de despido excluye que dicho trabajador pueda conservar su trabajo. 
del art. 8 (derecho al respeto de la vida privada y familiar) del CEDH, no como un supuesto de discriminación asociado al ejercicio de los derechos fundamentales (art. $14 \mathrm{CEDH).} \mathrm{La} \mathrm{óptica} \mathrm{adoptada} \mathrm{por} \mathrm{el} \mathrm{TJUE,} \mathrm{conservando}$ algunos elementos en común con la del TEDH en lo relativo a la potestad de los tribunales de ponderar los requisitos normativos respecto del derecho del trabajador y de la autonomía de las confesiones religiosas, parece más contundente en la protección del trabajador.

Lo primero que hace el TJUE es afirmar el control judicial efectivo de las decisiones de las confesiones religiosas en relación con el cumplimiento de las condiciones establecidas por la directiva sobre no discriminación, sin que un entendimiento expansivo del art. 17 TFUE pueda desvirtuar esta conclusión. Y para concretar la revisión de cumplimiento de dichas condiciones, sigue un esquema semejante al de la sentencia Egenberger, atendiendo a la naturaleza de las actividades que desempeña el trabajador y al contexto en el que se desarrollan las mismas, comprobando así el nexo entre el requisito profesional exigido y la actividad de que se trate, para poder en definitiva juzgar si ese requisito es esencial, legítimo y justificado respecto de la ética de la Iglesia u organización. A la vista de lo anterior, el TJUE llega a la conclusión de que una confesión religiosa (o entidad dependiente) no puede tratar de modo distinto a trabajadores con responsabilidades directivas en función de su pertenencia a una religión determinada excepto cuando, conforme a la directiva, estemos ante un requisito profesional esencial, legítimo y justificado en atención a la naturaleza de las actividades o al contexto en el que se desarrollen las mismas. En el presente asunto, a juicio del tribunal, el requisito controvertido es el carácter sagrado e indisoluble del matrimonio religioso. Pero la adhesión a ese principio no parece necesaria para la afirmación de la ética de IR, habida cuenta de las actividades profesionales que ejerce J.Q., que consisten en asesoramiento y asistencia médica en un hospital y la gestión del servicio de medicina interna (apdos. 57 y 58). Por lo demás, el tribunal afirma que corresponde al juez nacional valorar si la disposición nacional controvertida (art. 9 de la Ley de Igualdad de Trato alemana) se presta a una interpretación conforme con la Directiva, «dejando inaplicada, si es preciso, cualquier disposición de la normativa nacional contraria al principio de no discriminación por razón de la religión o de las convicciones» (apdo. 68).

Las dos decisiones examinadas han supuesto una doble revolución. Por un lado, afirman que los tribunales pueden revisar el contenido de las decisiones de las organizaciones religiosas, para comprobar que se ajustan a la excepción normativa, sin extender la noción de autonomía de las confesiones religiosas más allá de lo estrictamente indicado en el derecho de la Unión Europea o del Estado miembro. Por otro lado, ambas sentencias parecen 
reafirmar la tesis de la eficacia horizontal de la CDFUE (Ciacchi, 2019; Martí Sánchez, 2017: 10).

\subsection{Discriminación por motivos religiosos de empleados en virtud de normas estatales}

Bajo esta denominación examinamos una sentencia en la que se combina la interpretación de la Directiva 2000/78 con el art. 21 CDFUE sobre no discriminación.

La Ley sobre el Descanso laboral de Austria establece que el Viernes Santo es festivo o no laborable para los trabajadores que pertenezcan a las Iglesias Evangélicas de la confesión de Augsburgo y de la confesión helvética, de la Iglesia católica antigua ${ }^{31}$ y de la Iglesia evangélica metodista. La razón de que se establezca esta regla particular es ajustarse a los días festivos de confesiones religiosas cristianas minoritarias, entre los que está el Viernes Santo. Además, conforme a la misma ley, el empleado perteneciente a esas confesiones minoritarias que desempeñe trabajo en día señalado como festivo tendrá derecho a una retribución específica por ese día, salvo que se hubiera acordado un descanso compensatorio ${ }^{32}$. Un empleado de una empresa austriaca de detectives privados (Cresco Investigation) que no pertenece a ninguna confesión religiosa enumerada en la Ley de Descanso laboral considera que no abonarle retribución extra por trabajos realizados el 3 de abril de 2015, Viernes Santo, es discriminatorio por razón de religión. En consecuencia, demanda a su empresa ante la justicia austriaca. El Tribunal Supremo de lo Civil y Penal, que conoce del recurso de casación interpuesto por Cresco contra la sentencia de apelación, plantea al TJUE si es compatible el régimen austriaco descrito con el art. 21 CDFUE y con la Directiva 2000/78, especialmente sus arts. 1 y 2.2.a) (discriminación directa); si la normativa austriaca se justificaría como medida necesaria en una sociedad democrática para proteger el derecho a la libertad de culto y si, en su caso, podría considerarse una medida de discriminación positiva a favor de minorías religiosas para garantizar la plena igualdad

31 La Iglesia católica antigua es consecuencia de un cisma o separación que se produjo respecto de la Iglesia católica romana en el siglo XIX con motivo del rechazo de la primacía del romano pontífice por parte de católicos de Europa central que pasaron a constituir la llamada Unión de Utrecht.

32 La cuestión del calendario laboral y la inclusión del domingo como día festivo se trató colateralmente en la Sentencia del Tribunal de Justicia de 12 de noviembre de 1996, Reino Unido/Consejo, C-84/94, EU:C:1996:431. 
en la vida profesional y prevenir o compensar las desventajas que se les ocasionen por motivos de religión frente a la mayoría de la población del país ${ }^{33}$.

El TJUE afirma que la normativa austriaca establece una diferencia de trato basada en la religión de los trabajadores, justificándose por la importancia del Viernes Santo para unas confesiones religiosas concretas. La concesión del día festivo, no obstante, no está sujeta a que el trabajador cumpla una obligación religiosa determinada, sino solo a su pertenencia formal a una de las iglesias enumeradas. Dependiendo de la adscripción religiosa, por tanto, se produce un tratamiento distinto de los trabajadores. Esta diferencia de trato, ¿está justificada conforme al art. 2.5 $5^{34}$ ? Tras adscribir la cuestión al «fuero externo» (i.e. manifestación externa de la creencia religiosa), el tribunal toma nota de que la ley sobre el descanso laboral admite ciertas medidas de acomodación razonable respecto de la observancia de ritos religiosos mediante el derecho de ausentarse del puesto de trabajo (apdo. 60), por lo que la concesión de día no laborable, en su caso remunerado, por motivo de adscripción religiosa no es una medida necesaria, de la que además no disfrutan los miembros de confesiones religiosas minoritarias que tengan sus festividades en días no contemplados ni en el calendario general del país ni en Viernes Santo. A lo que el tribunal añade que «mientras el legislador nacional no haya adoptado medidas que restablezcan la igualdad de trato, incumbe a los empleadores aplicar a los trabajadores que no pertenezcan a ninguna de dichas Iglesias un tratamiento idéntico al que las disposiciones controvertidas en el litigio principal reservan a los trabajadores miembros de alguna de las citadas Iglesias» (apdo. 83), es decir, el pago de la retribución específica del Viernes Santo. Ciertamente, la normativa austriaca es excepcional en el contexto europeo (Cañamares-Arribas, 2019: 10), no es una medida dirigida a preservar los privilegios de la religión mayoritaria, pero sí pone de manifiesto - aunque el TJUE se distancia del tema- que el derecho de la Unión Europea afecta a las relaciones entre el Estado y las confesiones religiosas de forma significativa, aun cuando quede a salvo el «estatuto» de las confesiones religiosas a que se refiere el art. 17 TFUE.

33 Sentencia del Tribunal de Justicia (Gran Sala) de 22 de enero de 2019, Cresco Investigation, C-193/17, EU:C:2019:43.

34 Art. 2.5.5. La presente directiva se entenderá sin perjuicio de las medidas establecidas en la legislación nacional que, en una sociedad democrática, son necesarias para la seguridad pública, la defensa del orden y la prevención de infracciones penales, la protección de la salud y la protección de los derechos y libertades de los ciudadanos. 


\section{OTRAS CUESTIONES: ASILO, DERECHO DE FAMILIA, DATOS PERSONALES Y PRESCRIPCIONES ALIMENTARIAS}

Esta sección recoge una miscelánea de resoluciones que afectan también a la regulación del fenómeno religioso en el derecho europeo.

En el año 2012 el TJUE revisa la interpretación de la Directiva 2004/83/ $\mathrm{CE}$ que establece normas mínimas sobre refugiados y derecho de asilo ${ }^{35}$, aplicada a un caso de persecución religiosa, una temática específica dentro del amplio campo del derecho de asilo (Pérez-Madrid, 2019) reconocido en el art. 18 CDFUE y de la que también conoce con frecuencia el TEDH ${ }^{36}$. Se trata de dos litigios entre la República Federal Alemana y nacionales pakistaníes miembros de la comunidad religiosa Ahmadía, con una difícil situación en Pakistán (Rodríguez Moya, 2015: 125-130). Se deniega a los dos pakistaníes el asilo por considerar que sus solicitudes son infundadas. Recurrida las resoluciones de los dos solicitantes de asilo, los procesos llegan hasta el Tribunal federal contencioso-administrativo, que suspende el procedimiento y plantea, atendiendo al contenido del art. 9.1 a) de la directiva ${ }^{37}$ y poniendo esta en relación con el art. $9 \mathrm{CEDH}$, varias cuestiones prejudiciales de las que destaco aquí: ¿únicamente existe una violación grave de la libertad religiosa cuando se ve afectado su contenido esencial? ¿Existe acto de persecución cuando la práctica de la religión en público en el país de origen implica un riesgo para la vida, la integridad física o la libertad física y, por este motivo, el solicitante renuncia a dicha práctica? ¿Depende la violación grave del juicio del solicitante, que entiende no poder renunciar a la práctica sin violentar su identidad religiosa, o depende del juicio de su comunidad religiosa? ¿Pueden existir otras limitaciones como consecuencia de circunstancias como la situación del país

35 Directiva 2004/83/CE del Consejo, de 29 de abril de 2004, por la que se establecen normas mínimas relativas a los requisitos para el reconocimiento y el estatuto de nacionales de terceros países o apátridas como refugiados o personas que necesitan otro tipo de protección internacional y al contenido de la protección concedida, DO L 304/12, 30 de septiembre de 2004.

36 Strasbough Consortium. Freedom of Conscience and religion at the European Copurt of Human Rights - Topics - Asylum. Disponible en https://www.strasbourgconsortium.org/topic.php?pageId=11\&topicId $=56$.

37 Art. 9 Actos de persecución 1. Los actos de persecución en el sentido de la sección A del art. 1 de la Convención de Ginebra deberán: a) ser suficientemente graves por su naturaleza o carácter reiterado como para constituir una violación grave de los derechos humanos fundamentales, en particular los derechos que no puedan ser objeto de excepciones al amparo del apdo. 2 del art. 15 del Convenio Europeo para la Protección de los Derechos Humanos y de las Libertades Fundamentales. 
de origen? El TJUE seguirá en parte el esquema establecido por Estrasburgo (i.e. existencia o no de injerencia), pero aplicando este esquema al art. $10 \mathrm{CD}$ FUE. De nuevo vuelve sobre la distinción forum internum y forum externum, entendiendo que la definición de religión del CEDH, del TEDH (Fernández Arribas, 2013: 20) y, por ende, de la CDFUE, es una "definición amplia», pero sin hacer referencia a las directrices de la ONU sobre solicitud de asilo por motivos religiosos (UNHCR-ACNUR, 2011: 141), en las que se distingue religión como creencia, religión como identidad y religión como forma de vida (Gunn, 2003; López-Sidro López, 2018: 131). Tras el examen de la directiva, el tribunal concluye que no toda injerencia en la libertad religiosa es acto de persecución; que un acto de persecución puede resultar de un menoscabo de la manifestación externa de la religión; y que para determinar qué constituye un acto de persecución las autoridades deberán comprobar si el interesado, al ejercer su libertad religiosa en el país de origen, corre riesgo real de ser perseguido o sometido a un trato inhumano o degradante. Por último, el temor del solicitante se puede considerar fundado cuando se estime razonable que, al regresar al país de origen, el interesado practicará actos religiosos que le expondrán a la persecución, pero que no puede esperarse razonablemente que el solicitante renuncie a los actos religiosos y que, en consecuencia, no sea necesario otorgarle asilo. Con ello, el tribunal supera una visión reduccionista de la libertad religiosa, conforme a la cual se salva lo más importante del ejercicio de este derecho fundamental si se puede disfrutar del forum internum, la libertad de creer, pero que el forum externum no goza de la misma relevancia.

El pluralismo jurídico, coexistencia de varios ordenamientos jurídicos dentro de un mismo territorio o que afectan a una misma comunidad humana, es una cuestión que atrae la atención no solo de los juristas, sino también de quienes observan con interés el papel de la religión en la esfera pública (Secretary of State for the Home Department, 2018; Lerner, 2011; Williams, 2008). El TEDH ha empezado a enfrentarse a esta cuestión en el área del derecho de familia ${ }^{38}$. Por su parte, el TJUE ha tenido ocasión de asomarse tímidamente mediante un Auto a esta cuestión con motivo de la interpretación del Reglamento (UE) 1259/2010 del Consejo sobe cooperación reforzada en

38 Sentencia de 19 de diciembre de 2018, Molla Sali v. Greece [GC], CE:ECHR:2018:1219JUD002045214, sobre la aplicación del derecho sucesorio islámico en Grecia; de 8 de diciembre de 2009, Muñoz Díaz v. Spain, CE:ECHR:2009:1208JUD004915107, sobre la pensión económica a una viuda de matrimonio gitano sin previo ni posterior matrimonio civil. 
el ámbito de la ley aplicable al divorcio y a la separación judicial ${ }^{39}$. Se trata de un matrimonio musulmán celebrado en Siria en 1999, entre contrayentes sirios que adquirieron la nacionalidad alemana. El matrimonio permaneció en Alemania hasta 2003, se trasladaron a Siria, pero regresan a Alemania en 2011. En 2013 el señor Mamisch manifestó a su esposa, la señora Sahyouni, su deseo de divorciarse y se procede al divorcio privado en Siria ante un tribunal religioso por medio de representante. En septiembre del mismo año, la señora Sahyouni firmó una declaración por la que aceptaba una compensación económica y en octubre el señor Mamisch solicitó en Alemania el reconocimiento del divorcio religioso. El Tribunal Superior Regional Civil y Penal de Múnich procede al reconocimiento en octubre. Sin embargo, el 14 de febrero de 2014 la señora Sahyouni solicitó la anulación de la resolución de reconocimiento por no cumplirse los requisitos legales. El Tribunal Superior Regional Civil y Penal de Múnich desestima esa solicitud, si bien poco después el tribunal suspende el procedimiento (cabe entender que contra la desestimación) y somete al TJUE varias cuestiones prejudiciales, inquiriendo si es aplicable al caso de divorcio privado islámico el Reglamento 1259/2010; si conforme al art. 8 del Reglamento es aceptable el acceso al divorcio en condiciones de desigualdad jurídica de los esposos, en abstracto y en concreto; y si resulta relevante a efectos de estimar la estructura discriminatoria la aceptación consentida de la esposa de una compensación. Algunos sectores esperaban que esta sentencia diera pie a un pronunciamiento acerca de la discriminación como límite al pluralismo jurídico (Negri, 2018). Pero el TJUE solo concluye que al proceder la resolución de divorcio de un tercer Estado no se aplica el Reglamento europeo. Distinto sería si el Derecho alemán remitiera al Reglamento europeo para resolver este tipo de supuestos, pero no constaba de los datos aportados por el tribunal a quo que así fuera (Caamiña Domínguez, 2017).

En 2018 se planteó una interesante cuestión relativa a la protección de datos personales, en una sentencia que se pronunció cuando ya entró en vigor el Reglamento general de protección de datos ${ }^{40}$, si bien rige para el caso la

39 Reglamento (UE) 1259/2010 del Consejo, de 20 de diciembre de 2010, por el que se establece una cooperación reforzada en el ámbito de la ley aplicable al divorcio y a la separación judicial, DO L 343/10, de 29 de diciembre de 2010.

40 Reglamento (UE) 2016/679 del Parlamento Europeo y del Consejo, de 27 de abril de 2016, relativo a la protección de las personas físicas en lo que respecta al tratamiento de datos personales y a la libre circulación de estos datos y por el que se deroga la Directiva 95/46/CE (Reglamento general de protección de datos), DO L 119/1, 4 de mayo de 2016. 
Directiva 95/46/CE ${ }^{41}$ cuya interpretación se contrasta con el art. 10 CDFUE (Rodríguez García, 2019). En 2013, la Comisión de protección de datos de Finlandia adoptó una resolución prohibiendo a la Comunidad de los Testigos de Jehová la recogida de datos personales con motivo de la predicación puerta a puerta de sus fieles. Consideraba dicha comisión que la recogida de datos de visitas realizadas (nombre, dirección, convicciones religiosas, etc., datos que se recopilan sin conocimiento de los visitados) estaba incluida y contravenía la norma nacional de trasposición de la directiva europea ya que no es tratamiento de datos personales efectuado por una persona física para fines personales. La Comunidad de los Testigos de Jehová recurre la decisión y obtiene una sentencia favorable en primera instancia; el supervisor de protección de datos recurre al Tribunal Supremo de lo Contencioso-Administrativo, que suspende el procedimiento y somete al TJUE unas cuestiones prejudiciales que sintetizo $^{42}$ : ¿podemos considerar que esta recogida de datos corresponde a lo que en la mencionada directiva es recogida de datos por una persona física para fines exclusivamente personales? ¿Debe considerarse "fichero» el conjunto de datos recogidos de forma no automatizada en relación con la actividad de predicación puerta a puerta? ¿Puede considerarse a la Comunidad de Testigos de Jehová responsable de la recogida de datos, pese a que solo acceden a los datos algunos miembros del grupo religioso? ¿Puede considerarse a la Comunidad de Testigos de Jehová encargada del tratamiento conforme al art. 2 de la Directiva mencionada ${ }^{43}$ si adopta medidas específicas respecto de los datos, o basta que desempeñe un papel directivo en la actividad de sus fieles?

A los efectos que aquí interesan, el TJUE indica que la actividad que llevan a cabo los fieles de la Comunidad de Testigos de Jehová está protegida por

41 Directiva 95/46/CE del Parlamento Europeo y del Consejo, de 24 de octubre de 1995 , relativa a la protección de las personas físicas en lo que respecta al tratamiento de datos personales y a la libre circulación de estos datos, DO L 281, 23 de noviembre de 1995.

42 Sentencia del Tribunal de Justicia (Gran Sala) de 10 de julio de 2018, Jehovan todistajat, C-25/17, EU:C:2018:551.

43 Art. 2. Definiciones. A efectos de la presente Directiva, se entenderá por: [...] d) «responsable del tratamiento»: la persona física o jurídica, autoridad pública, servicio o cualquier otro organismo que solo o conjuntamente con otros determine los fines y los medios del tratamiento de datos personales; en caso de que los fines y los medios del tratamiento estén determinados por disposiciones legislativas o reglamentarias nacionales o comunitarias, el responsable del tratamiento o los criterios específicos para su nombramiento podrán ser fijados por el derecho nacional o comunitario [...]. 
el art. $10 \mathrm{CDFUE}^{44}$, pero esta circunstancia no confiere a la actividad carácter personal o doméstico. Los datos recogidos constituyen un "fichero», pues esta denominación no depende de la automatización del tratamiento. «El concepto de "fichero", definido en esa disposición, comprende un conjunto de datos personales recogidos en relación con una actividad de predicación puerta a puerta, consistentes en nombres, direcciones y otra información relativa a las personas contactadas, siempre que los datos estén estructurados según criterios determinados que permitan, en la práctica, recuperarlos fácilmente para su utilización posterior. Para que dicho conjunto de datos esté comprendido en ese concepto no es preciso que incluya fichas, catálogos específicos u otros sistemas de búsqueda» (apdo. 62). Entiende igualmente el tribunal que la confesión religiosa "participa, junto con sus miembros predicadores, en la determinación de la finalidad y de los medios de los tratamientos de datos personales de las personas contactadas, extremo que, sin embargo, corresponde verificar al órgano jurisdiccional remitente a la vista de todas las circunstancias del caso de autos» (apdo. 73), por lo que no puede excluirse a priori que sea responsable, circunstancia que "no se desvirtúa por el principio de autonomía organizativa de las comunidades religiosas que se desprende del art. 17 TFUE. En efecto, la obligación que incumbe a todas las personas de cumplir las normas del Derecho de la Unión en materia de protección de datos personales no puede considerarse una injerencia en la autonomía organizativa de las comunidades religiosas» (apdo. 74). En conclusión, todo apunta a que la Comunidad de Testigos de Jehová es responsable de los datos y que no cabe una interpretación de la directiva muy distinta de la que hicieron las autoridades nacionales.

A continuación, corresponde analizar dos sentencias relativas a las prescripciones dietéticas religiosas, separadas entre sí por menos de un año. El TEDH se había pronunciado ya casi veinte años antes sobre el control estatal del sacrificio ritual de animales para el consumo ${ }^{45}$.

La novedad del caso del año 2018 consiste en que se plantea la validez de una norma europea en relación con el derecho fundamental de libertad religiosa reconocido por la CDFUE y por el CEDH. Con motivo de la fiesta islámica del sacrificio, un elevado número de musulmanes en Bélgica tienen

44 A este respecto, la predicación puerta a puerta es parte del derecho de libertad religiosa y no puede someterse a permiso previo en el caso ante el Tribunal Supremo de los Estados Unidos Watchtower Bible \& Tract Society of New York, Inc. v. Village of Stratton, 536 U.S. 150 (2002).

45 Sentencia del TEDH de 7 de junio de 2000, Cha'are Shalom Ve Tsedek v. France [GC], CE:ECHR:2000:0627JUD002741795. 
el deber religioso de sacrificar o hacer que se sacrifique un animal (preferentemente una vaca o un cordero) que se distribuye entre la familia y los necesitados, vecinos o parientes lejanos. El sacrificio del animal debe realizarse conforme a un rito religioso y sin aturdimiento previo. Tanto el Reglamento (CE) 1099/200946 relativo a la protección de los animales en el momento de la matanza como la normativa belga sobre protección y bienestar animal contienen excepciones por razones religiosas al deber de aturdimiento de animales para el consumo humano. El Reglamento apenas enuncia la cuestión, solo exige en su art. 4.4 que el sacrificio religioso, definido previamente en el art. $2^{47}$, se lleve a cabo en un matadero y deja el asunto a la determinación de las legislaciones nacionales ${ }^{48}$. La normativa belga exige que el sacrificio ritual religioso se lleve a cabo en mataderos regularmente autorizados y en mataderos temporales autorizados por el Ministerio de asuntos agrícolas previo acuerdo con el Ministerio encargado de salud pública. Desde 1998, Bélgica había autorizado mataderos temporales para poder atender a la demanda con motivo de la fiesta musulmana. Sin embargo, después de transferirse las competencias de agricultura a las regiones, en 2015 el ministro de la región de Flandes entiende que los mataderos temporales contravienen el Reglamento europeo. Las comunidades musulmanas presentan entonces en 2016 un pleito ante el Tribunal de Primera Instancia de Lengua Neerlandesa de Bruselas contra la región de Flandes, alegando que el Reglamento europeo excluye de su aplicación el sacrificio de animales durante acontecimientos culturales y deportivos $^{49}$, lo que entienden que comprende también el sacrificio ritual y, subsidiariamente, defendiendo que la restricción del Reglamento en su art. 4.4

46 Reglamento (CE) 1099/2009 del Consejo, de 24 de septiembre de 2009, relativo a la protección de los animales en el momento de la matanza, DO L 303/1, 18 de noviembre de 2009.

47 Art. 2 Definiciones. A efectos del presente Reglamento se aplicarán las siguientes definiciones: [...] g) «rito religioso»: serie de actos relacionados con el sacrificio de animales, prescritos por una religión $[\ldots]$.

48 Art. 4. Métodos de aturdimiento. 1. Los animales se matarán únicamente previo aturdimiento, con arreglo a los métodos y requisitos específicos correspondientes a la aplicación de dichos métodos previstos en el anexo I. Se mantendrá la pérdida de consciencia y sensibilidad hasta la muerte del animal. [...] 4. En el caso de animales que sean objeto de métodos particulares de sacrificio prescritos por ritos religiosos, no serán de aplicación los requisitos del apdo. 1, a condición de que el sacrificio se lleve a cabo en un matadero.

49 Art. 1. Objeto y ámbito de aplicación [...] 3. El presente Reglamento no se aplicará: a) si los animales son matados: [...] iii) durante acontecimientos culturales o deportivos; [...]. 
contraviene el art. 10 CDFUE. El tribunal belga se encuentra en una cierta situación de perplejidad. Por un lado, el sacrificio es propiamente un rito religioso, pero, por otro lado, la restricción del Reglamento a los mataderos autorizados es una restricción al ejercicio de la libertad religiosa. ¿Podría entonces considerarse que el art. 4 del Reglamento contraviene los arts. 10 CDFUE, 9 CEDH y 13 TFUE ${ }^{50}$ ?

De la revisión del Reglamento, el tribunal llega a la conclusión de que el sacrificio ritual es un rito religioso, dejando de lado sutilezas teológicas internas acerca de la relevancia o no del aturdimiento. Al establecer la obligación del sacrificio ritual en un matadero autorizado, sostiene el TJUE, se pretende dar cauce legal al libre ejercicio del sacrificio sin aturdimiento con fines religiosos, pero este «encuadramiento técnico no implica, en sí mismo, una limitación del derecho de libertad de religión de los musulmanes practicantes» (apdo. 59). Lo cual no deja de ser sorprendente, porque — volviendo sobre un razonamiento anterior acerca de la injerencia en el ejercicio del derecho fundamental examinado- parece claro que la normativa dificulta la celebración del sacrificio y el abastecimiento a los seguidores del islam en Flandes. Pero el tribunal despacha la cuestión con firmeza: «[...] la problemática puesta de manifiesto por el órgano jurisdiccional remitente, a la que se hace mención en el apdo. 70 de la presente sentencia, concierne únicamente a un número limitado de municipios de la región de Flandes. En consecuencia, dicha problemática no puede considerarse intrínsecamente vinculada a la aplicación, en toda la Unión, de la norma del art. 4, apdo. 4». Es decir, que la limitación del ejercicio del derecho fundamental en una zona de la Unión Europea — da la impresión— es una cuestión numérica, reduciendo la injerencia o infracción de los derechos humanos a una regla de mínimo impacto (Watson y Oliver, 2019: 861). Cierto es que las comunidades islámicas podrían invertir en la adaptación o construcción de nuevos mataderos permanentes que cumplan las condiciones para satisfacer la demanda de la fiesta, pero esto significaría incurrir en un gasto desproporcionado, gravando de forma indirecta el libre ejercicio de la religión. Sin embargo, no lo ve así el tribunal: «[...] las dudas expresadas por el órgano jurisdiccional remitente acerca de la posible vulneración de la libertad de religión a causa de la carga financiera desproporcionada que recaería sobre las comunidades musulmanas afectadas

50 Art. 13. Al formular y aplicar las políticas de la Unión en materia de agricultura, pesca, transporte, mercado interior, investigación y desarrollo tecnológico y espacio, la Unión y los Estados miembros tendrán plenamente en cuenta las exigencias en materia de bienestar de los animales como seres sensibles, respetando al mismo tiempo las disposiciones legales o administrativas y las costumbres de los Estados miembros relativas, en particular, a ritos religiosos, tradiciones culturales y patrimonio regional. 
son infundadas y no desvirtúan la consideración [...] de que la norma del art. 4, apdo. 4, del Reglamento 1099/2009, en relación con el art. 2, letra k), del mismo, no implica, en sí misma, una limitación del derecho de libertad de religión de los musulmanes, garantizado por el art. 10 de la Carta» (apdo. 79). Por lo demás, entiende también el tribunal que el art. 4.4 no guarda relación con el art. 13 TFUE, conforme al cual al formular y aplicar las políticas en materia de agricultura, la Unión tendrá en cuenta el bienestar de los animales como seres sensibles respetando las costumbres de los Estados relativas a los ritos religiosos y culturales; «de los autos remitidos al Tribunal de Justicia no resulta claramente cuáles serían las disposiciones legislativas o administrativas y las costumbres belgas relativas al rito religioso de la Fiesta del Sacrificio que resultan del art. 13 TFUE» (apdo. 82). La conclusión resulta un tanto sorprendente y obliga de inmediato a preguntarnos acerca de cuáles serían entonces los ritos religiosos y culturales relevantes en el art. 13: ¿solo los centenarios cristianos? ¿Los milenarios paganos? En definitiva, de la sentencia cabe concluir que la excepción al sacrificio animal sin aturdimiento se acepta en el contexto de la Unión Europea, pero que tiene un carácter restrictivo (García Ureta, 2019:297) prevalente sobre consideraciones fundadas en el derecho de libertad religiosa.

En la segunda de las sentencias sobre sacrificio ritual de animales ${ }^{51}$, de 2019, cambia la perspectiva, pues de lo que se trata en esta ocasión es de la aplicación del Reglamento (CE) 889/2008 sobre producción y etiquetado de productos ecológicos ${ }^{52}$. La normativa francesa recoge la mención «agricultura ecológica» para designar los productos agrícolas que cumplan las normas europeas especiales sobre producción y etiquetado. Una asociación francesa de protección de animales presenta una solicitud para conseguir que la mención le sea retirada a la carne «halal» (certificación musulmana) que procede de animales sacrificados sin aturdimiento previo. Las solicitudes fueron desestimadas implícitamente y la asociación solicitante no logra la anulación de la resolución ante el Consejo de Estado francés. La asociación presenta entonces una demanda ante el Tribunal de Apelación de lo Contencioso-Administrativo de Versalles, alegando que en los productos procedentes de animales sacrificados sin aturdimiento previo no puede constar la mención, puesto que ese método de sacrificio no cumple el requisito de normas de bienestar animal, y que la

51 Sentencia del Tribunal de Justicia (Gran Sala) de 26 de febrero de 2019, Euvre d'assistance aux bêtes d'abattoirs, C-497/17, EU:C:2019:137.

52 Reglamento (CE) 889/2008 de la Comisión, de 5 de septiembre de 2008, por el que se establecen disposiciones de aplicación del Reglamento (CE) 834/2007 del Consejo sobre producción y etiquetado de los productos ecológicos, con respecto a la producción ecológica, su etiquetado y su control, DO L250/1, 18 de septiembre de 2008. 
excepción del art. 4, apdo. 4, del Reglamento 1099/2009 permite establecer una excepción a la norma general del aturdimiento previo, pero tal excepción responde únicamente a objetivos de control sanitario y de igualdad de trato de las creencias y las tradiciones religiosas. El Tribunal de Apelación francés consigna que ninguna disposición de los Reglamentos 834/2007, 889/2008 y 1099/2009 define los modos de sacrificio adecuados para el bienestar animal y reducción del sufrimiento que se establecen para la producción ecológica, por lo que estrictamente no puede excluirse de la mención ecológica la carne procedente de animales que hayan sido objeto de un sacrificio ritual sin aturdimiento previo: hay, por tanto, un problema de interpretación del derecho europeo. En consecuencia, el art. 13 TFUE y los reglamentos citados, ¿autorizan o prohíben la mención especial para los productos procedentes de animales sacrificados de forma ritual sin aturdimiento previo? Es la cuestión que se plantea al TJUE, quien subraya que el sacrificio ritual sin aturdimiento previo tiene carácter excepcional y pretende garantizar la libertad religiosa, pero que conforme a los criterios científicos no es tan eficaz para reducir el dolor, la angustia o el sufrimiento del animal como el sacrificio precedido de aturdimiento, práctica que conforme a la normativa europea es necesaria para causar en el animal una pérdida de consciencia y de sensibilidad que reduzca considerablemente el sufrimiento. De suyo, los métodos de sacrificio ritual que exceptúa el art. 4 del Reglamento 1099/2009 no equivalen a un alto nivel de protección del bienestar animal en el momento de la matanza, que es el presupuesto que garantiza la etiqueta ecológica a los consumidores. En consecuencia, la normativa europea no autoriza la utilización del logotipo ecológico en productos procedentes de animales sacrificados sin aturdimiento previo. Quizá a raíz de esta sentencia, y de la cuestión subyacente, podría aventurarse un nuevo reglamento europeo que especifique de forma precisa los requisitos del bienestar animal en orden al sacrificio para el consumo (Zanini, 2019: 225).

\section{CONCLUSIONES: ALGUNOS RASGOS DESTACABLES DE LA JURISPRUDENCIA EN TORNO A LA RELIGIÓN Y LAS CREENCIAS}

Pasemos a continuación a extraer algunas conclusiones que se desprenden de esta significativa serie de pronunciamientos del TJUE que guardan relación con la religión y las creencias ${ }^{53}$.

53 Queda al margen de la exposición la Sentencia del Tribunal de Justicia de 14 de noviembre de 2018, Memoria y Dall'Antonia, C-342/17, EU:C:2018:906, sobre 
La amplia variedad de aspectos que en un plazo breve de tiempo se ha planteado ante el Tribunal de Justicia de la Unión Europea es llamativa. Dada la naturaleza de la función de dicho tribunal, no se limita a contrastar el derecho fundamental de libertad religiosa con la actuación de las autoridades de la Unión o de los Estados en la aplicación del derecho europeo, sino que están en juego otras muchas materias que entran en contacto con la religión o las creencias, individuales y colectivas. Todavía es pronto para determinar si estamos ante una explosión aislada de casos ante el TJUE o si, como ocurrió con el TEDH, comienza ahora toda una nueva etapa en la que el TJUE procede a interpretar el derecho o resolver problemas en los que religión y creencias son factores determinantes de los nuevos supuestos.

En este sentido, como hemos tenido ocasión de comprobar, tiene un papel de primer orden la igualdad y la no discriminación en el empleo. En este ámbito hay una tensión entre no discriminación y libertad religiosa de gran interés para el futuro (Vickers y European Commission, 2007: 8) y una diferencia de criterios entre el TJUE y el TEDH a la hora de valorar la discriminación indirecta (McCrea, 2016: 201) y la viabilidad de la acomodación razonable en la esfera de la religión y las creencias. Si en algún momento se pudo albergar una sospecha de que el art. 17 TFUE lograba blindar supuestas prácticas discriminatorias y antidemocráticas de las confesiones religiosas cristianas, de las sentencias estudiadas puede deducirse que tal sospecha no está fundada en la medida en la que la autonomía de las confesiones religiosas se ve interpretada de forma restrictiva en relación con los puestos de trabajo en entidades inspiradas o dirigidas por las confesiones religiosas.

En el conjunto de sentencias analizadas, el concepto de neutralidad religiosa aparece en varios contextos. Uno de ellos es precisamente el relativo al art. 17 TFUE. En él, el TJUE contempla una «neutralidad de la Unión respecto a la organización por parte de los Estados miembros de sus relaciones con las iglesias y asociaciones o comunidades religiosas" (Egenberger, apdo. 58). El otro contexto es el relativo a la neutralidad como parte de la identidad voluntariamente asumida por la empresa privada. Aquí la doctrina académica sostiene con razón que el TJUE ha admitido este fin legítimo frente a la no discriminación por motivos religiosos y frente a la libertad religiosa de forma un tanto acrítica, otorgando un blindaje frente a la no discriminación de minorías religiosas. Parece que el tribunal también suscribe la neutralidad respecto de la valoración del contenido de las creencias, pues descarta entrar

restricciones normativas sobrevenidas a la custodia de urnas cinerarias por parte de una empresa mercantil, pues no aparecen connotaciones religiosas directas en todo el asunto. 
en debates teológicos relativos a cuestiones religiosas (Liga van Moskeeën en Islamitische Organisaties Provincie Antwerpen y otros, apdo. 50). Por lo demás, la neutralidad tiene una finalidad instrumental, una garantía para que los poderes públicos no interfieran ni favorezcan indebidamente el libre ejercicio de la religión y las creencias.

En general, la postura del TJUE es respetuosa hacia la religión y las creencias, no entra en la calificación de nuevos movimientos religiosos que pueden resultar poco comunes. A la hora de determinar la noción de religión en el derecho europeo, el tribunal ha recurrido a la distinción entre forum internum y forum externum presente en el TEDH. Con ello, se ha quedado en la superficie de la cuestión, pues esos términos solo apuntan a las dimensiones de lo protegido por la libertad religiosa, no a su contenido. Y, sin embargo, subsiste de fondo en los planteamientos del Tribunal de Luxembugo una larvada tensión entre religión como identidad y religión como opción, tensión que quizá le acompañará también en futuras decisiones. Y desde luego resulta un poco desconcertante que en Liga van Moskeeën en Islamitische Organisaties Provincie Antwerpen y otros la injerencia en la libertad religiosa de las comunidades musulmanas se reconduzca a un problema local y numérico y no se reconozca la injerencia en la libertad religiosa.

\section{Bibliografía}

Aznar García, S. (2017). La compatibilidad de la exención del impuesto sobre construcciones, instalaciones y obras de la Iglesia Católica con el derecho comunitario: comentario a la Sentencia de la Gran Sala del Tribunal de Justicia de la Unión Europea de 27 de junio de 2017. Revista General de Derecho Canónico y Derecho Eclesiástico del Estado, 45. Disponible en: https://bit.ly/2v8A4fr.

Baldi, G. (2018). Re-Conceptualizing Equality in the Work Place: A Reading of the Latest CJEU's Opinions over the Practice of Veiling. Oxford Journal of Law and Religion, 7 (2), 296-312. Disponible en: https://doi.org/10.1093/ojlr/rwy028.

Barnett, J. (2005). A Theology for Europe: The Churches and the European Institutions. Oxford: Peter Lang.

Bribosia, E., Ringelheim, J. y Rorive, I. (2010). Reasonable Accommodation for Religious Minorities: A Promising Concept for European Antidiscrimination Law? Maastricht Journal of European and Comparative Law, 17 (2), 137-161. Disponible en: https://doi.org/10.1177/1023263X1001700203.

Caamiña Domínguez, C. M. (2017). Divorcio privado dictado por un tribunal religioso de un tercer estado: Asunto c-281/15 Soha Sahyouni y Raja Mamisch $=$ Private divorce pronounced by a religious court in a third country: Case c-281/15, Soha Sahyouni v Raja Mamisch. Cuadernos de Derecho Transnacional, 9 (2), 629-634. Disponible en: https://doi.org/10.20318/cdt.2017.3891. 
Cañamares-Arribas, S. (2017). Discriminación laboral por razón de religión en el Derecho comunitario europeo. Revista de Derecho del Trabajo, 16, 49-63.

Cañamares-Arribas, S. (2019). Religión y relaciones laborales en las entidades públicas y privadas en España. Ius Canonicum, 59 (118), 1-36. Disponible en: http://doi.org/10.15581/016.118.004.

Castro Jover, A. (2011). La tutela de la libertad religiosa en la Unión Europea y su incidencia en el ordenamiento interno español. En M. ${ }^{a}$ C. Barranco Avilés, Ó. Celador Angón y F. Vacas Fernández (coords.). Perspectivas actuales de las fuentes del derecho (pp. 95-120). Madrid: Dykinson.

Cebriá García, M. (2017). La exención en el ICIO de la Iglesia Católica en el estado español y la prohibición de ayudas de estado del derecho de la Unión Europea. Revista General de Derecho Canónico y Derecho Eclesiástico del Estado, 45. Disponible en: https://bit.ly/2vkxuCO.

Celador Angón, O. (2011). Libertad de conciencia y Europa: un estudio sobre las tradiciones constitucionales comunes y el Convenio Europeo de Derechos Humanos. Madrid: Dykinson.

Cerutti, F. y Rudolph, E. (2001). A Soul for Europe: A Reader. Leuven: Peeters Publishers.

Ciacchi, A. (2019). The Direct Horizontal Effect of EU Fundamental Rights: ECJ 17 April 2018, Case C-414/16, Vera Egenberger v Evangelisches Werk Für Diakonie Und Entwicklung e.V. and ECJ 11 September 2018, Case C-68/17, IR v J.Q.. European Constitutional Law Review, 15 (2), 294-305. Disponible en: https://doi.org/10.1017/S1574019619000154.

Contreras Mazarío, J. (2017). El TJUE no prohíbe el uso del velo islámico. Comentario a las sentencias del TJUE de 14 de marzo de 2017, asuntos C-157/15 y C-188/15. Revista de Derecho Comunitario Europeo, 57. Disponible en: http:// doi.org/10-18042/cepc/rdce.57.05.

Doe, N. (2011). Law and religion in Europe: a comparative introduction. Oxford: Oxford University Press. Disponible en: https://doi.org/10.1093/acprof:oso/9780199604005.001.0001.

Durham, W. (2006). La importancia de la experiencia española en las relaciones Iglesia-Estado para los países en transición. En J. Martínez-Torrón (ed.). Estado y Religión en la Constitución Española y en la Constitución Europea: Actas del Seminario Internacional Complutense celebrado en la Facultad de Derecho de la Universidad Complutense, Madrid, 14 de mayo de 2004 (pp. 43-68). Granada: Comares.

Félix Ballesta, M. y Martínez Félix, C. (2007). ¿Es contraria al Derecho Comunitario la exención del impuesto sobre construcciones, instalaciones y obras (ICIO), de que goza la Iglesia Católica en España? Cuadernos de Integración Europea, 7, 65.

Fernández Arribas, G. (2013). La concesión del estatuto de refugiado debido al riesgo de ser perseguido por motivos religiosos: sentencia del Tribunal de Justicia de la Unión Europea, de 5 de septiembre de 2012, en el Asunto Y y Z. Revista General de Derecho Europeo, 31, 11. Disponible en: https://bit.ly/2viGY1p. 
Fernández-Coronado González, A. (2002). El Derecho de la libertad de conciencia en el marco de la Unión Europea: pluralismo y minorias. Madrid: Colex.

Fokas, E. (2016). Comparative Susceptibility and Differential Effects on the Two European Courts: A Study of Grasstops Mobilizations around Religion. Oxford Journal of Law and Religion, 5 (3), 541-574. Disponible en: http://doi. org/10.1093/ojlr/rww050.

García Ureta, A. (2019). Jurisprudencia del Tribunal de Justicia de la Unión Europea sobre los sacrificios religiosos de animales. Revista Vasca de Administración Pública. Herri-Arduralaritzako Euskal Aldizkaria, 114, 273-298.

Giles, J. (2018). Neutrality in the Business Sphere-An Encroachment on Rights Protection and State Sovereignty? Oxford Journal of Law and Religion, 7 (2), 339-346. Disponible en: https://doi.org/10.1093/ojlr/rwy026.

González Sánchez, M. (2019). La condición de monje no impide ejercer como abogado en la Unión Europea: Sentencia del Tribunal de Justicia (Gran Sala), de 7 de mayo de 2019, asunto C-431/17: Monje Ireneo v. Colegio de Abogados de Atenas. La Ley Unión Europea, 72, 5.

Gunn, T. J. (2003). The Complexity of Religion and the Definition of «Religion» in International Law. Harvard Human Rights Journal, 16, 189-216.

Hogebrink, L. (2015). Europe's Heart and Soul: Jacques Delors' Appeal to the Churches (vol. 2). Geneva: Globethics.net.

Howard, E. (2007). Religious Clothing and Symbols in Employment. Luxembourg: Publications Office of the European Union.

Ibán Pérez, I. (2006). La protección de la libertad religiosa en la Unión Europea. Revista Jurídica Universidad Autónoma de Madrid, 14, 296-305.

Iglesias Vázquez, M. (2015). La protección del derecho a la libertad de pensamiento, de conciencia y de religión en la jurisprudencia del Tribunal de Justicia de la Unión Europea: Análisis comparativo con el Tribunal Europeo de Derechos Humanos. En I. Cano (ed.). Identidad religiosa y relaciones de trabajo. Un estudio de la jurisprudencia del Tribunal Europeo de Derechos Humanos (pp. 127-152). Granada: Comares.

Landete Casas, J. (2007). La libertad religiosa en el Derecho Comunitario. Cuadernos de Integración Europea, 7, 19.

Leal Adorna, M. (2018). Los símbolos religiosos: el Tribunal de Justicia de la Unión Europea y el uso del velo islámico en las relaciones laborales privadas. Revista General de Derecho del Trabajo y de la Seguridad Social, 51, 385-420. Disponible en: https://bit.ly/37TZ8nC.

Lerner, N. (2011). Group Rights and Legal Pluralism. Emory International Law Review, 25 (2), 829-851.

Leustean, L. (2016). The Representation of Religion in the European Union. En J. Chaplin y G. Wilson (eds.). God and the EU. Faith in the European Union (p. 175). London: Routledge.

Lillo, P. (2018). Rilevanza pubblica delle comunità religiose nella dimensione giuridica europea. Stato, Chiese e Pluralismo Confessionale, 28. 
López-Sidro López, A. (2018). Asilo y libertad religiosa en la jurisprudencia española y europea. Derecho y Religión, 13, 127-152.

Martí Sánchez, J. (2017). Comentario a la Sentencia del Tribunal de Justicia (Gran Sala) de la Unión Europea (TJUE) de 14 de marzo de 2017, Asma Bougnaoui, Association de défense des droits de l'homme (ADDH) y Micropole SA. Revista General de Derecho Canónico y Derecho Eclesiástico del Estado, 44. Disponible en: https://bit.ly/2PqGA8d.

Martín y Pérez de Nanclares, J. (2008). Comentario art. 10. En A. Mangas Martín (ed.). Carta de los Derechos Fundamentales de la Unión Europea: comentario artículo por artículo (pp. 257-270). Bilbao: Fundación BBVA.

Martínez-Torrón, J. (2016). European Convention on Human Rights. En Encyclopedia of Law and Religion (pp. 173-185). Leiden: Martinus Nijhoff-Brill.

Matlak, M. (2018). Jacques Delors: The Single Market and the Failed Attempt to Give 'a Soul to Europe'. Robert Schuman Centre for Advanced Studies, Working Paper, 6. Disponible en: https://doi.org/10.2139/ssrn.3157116.

McCrea, R. (2016). Singing from the Same Hymn Sheet? What the Differences between the Strasbourg and Luxembourg Courts Tell Us about Religious Freedom, Non-Discrimination, and the Secular State? Oxford Journal of Law and Religion, 5 (2), 183-210. Disponible en: https://doi.org/10.1093/ojlr/ rwv067.

Meseguer Velasco, S. (2019). Financiación de la religión en Europa. Madrid: Digital Reasons.

Motilla, A. (1990). Sectas y derecho en España: un estudio en torno a la posición de los nuevos movimientos religiosos en el orden jurídico. Madrid: Edersa.

Negri, A. (2018). La Sentenza Sahyouni c. Mamish Della Corte Di Giustizia Di Lussemburgo: Un'occasione per Tornare a Riflettere Sulla Portata Del Principio Di Non Discriminazione Nell'ordinamento Dell'Unione Europea (EU Court of Justice's Sahyouni v. Mamisch Judgment: An Opportunity to Reflect on the Centrality of the Non-Discrimination Principle in EU Law). SSRN Scholarly Paper. ID 3300076. Rochester, N. Y.: Social Science Research Network. Disponible en: https://doi. org/10.2139/ssrn.3300076.

Nuevo López, P. (2017). Derecho antidiscriminatorio, libertad religiosa y relaciones entre particulares en el derecho de la Unión Europea. Estudios de Deusto: Revista de la Universidad de Deusto, 65 (2), 389-404. Disponible en: https://doi. org/10.18543/ed-65(2)-2017pp. 389-404.

Pasikowska-Schnass, M. (2018). Article 17 TFEU: The EU Institutions's Dialogue with Confessional and Non-Confessional Organizations. European Parliamentary Research Service.

Pavlidou, K. (2018). Religious Expression in the Workplace Before the European Court of Human Rights and the Court of Justice of the European Union: Discriminating Against a Fundamental Right? En D. Goulas y S. Kofinis (eds.). Applying Non-Discrimination Law (pp. 146-163). Thessaloniki: Hellenic League for Human Rights. 
Pelayo Olmedo, D. (2017). La prohibición del uso de prendas y símbolos religiosos en el ámbito laboral: Aclaraciones del TJUE sobre la aplicación del principio de igualdad y no discriminación en el caso Samira Achbita c. G4S Secure Solutions NV. Revista General de Derecho Europeo, 43, 7. Disponible en: https://bit. ly/2Thyb88.

Pérez-Madrid, F. (2019). Derecho de asilo y libertad religiosa. Cizur Menor: Aranzadi. Polo Sabau, J. (2014). El estatuto de las confesiones religiosas en el derecho de la Unión Europea: entre el universalismo y la peculiaridad nacional. Madrid: Dykinson.

Polo Sabau, J. (2018). Estado y confesiones religiosas en el Derecho de la Unión Europea: la repercusión del art. 17 del Tratado de Funcionamiento de la Unión Europea en la jurisprudencia del TJUE. Revista General de Derecho Europeo, 46. Disponible en: https://bit.ly/3c7nXjb.

Relaño Pastor, E. (2016). Towards Substantive Equality for Religious Believers in the Workplace? Two Supranational European Courts, Two Different Approaches. Oxford Journal of Law and Religion, 5 (2), 255-279. Disponible en: https://doi. org/10.1093/ojlr/rww020.

Rodrigues Araújo, A. (2012). Iglesias y organizaciones no confesionales en la Unión Europea: el art. 17 del TFUE. Pamplona: Ediciones Universidad de Navarra, S. A.

Rodríguez Blanco, M. (2017). La neutralidad del empresario como límite a la libertad religiosa del trabajador (Comentario a las sentencias de la Gran Sala del Tribunal de Justicia de la Unión Europea de 14 de marzo de 2017). Foro: Revista de Ciencias Jurídicas y Sociales, 20 (1), 383-397. Disponible en: https:// doi.org/10.5209/FORO.57543.

Rodríguez García, J. A. (2019). Autonomía de las confesiones y derecho comunitario: La protección de los datos personales en este contexto. Revista General de Derecho Canónico y Derecho Eclesiástico del Estado, 49. Disponible en: https:// bit.ly/2T2H7zo.

Rodríguez Moya, A. (2015). Asylum and Religious Freedom. The ECJ Position. Revista de Derecho Político, 94, 115-140. Disponible en: https://doi.org/10.5944/ rdp.94.2015.15739.

Sandberg, R. (2011). The Right to Discriminate. Ecclesiastical Law Journal, 13 (02), 157-181. Disponible en: https://doi.org/10.1017/S0956618X11000044.

Secretary of State for the Home Department (2018). The Independent Review into the Application of Sharia Law in England and Wales. London: Counter Extremism Unit, Home Office. Disponible en: http://www.gov.uk/government/publications.

Stein, A. (2014). Reasonable Accommodation for Religion and Belief: Can it Be Accommodated in EU Law without an Express Duty? En M.-C. Foblets, K. Alidadi, J. S. Nielsen y Z. Yanasmayan. Belief, Law and Politics: what future for a secular Europe? Cultural diversity and law in association with RELIGARE (pp. 171-180). Farnham, Surrey: Ashgate.

UNHCR-ACNUR. (2011). Manual y Directrices sobre Procedimientos y Criterios para Determinar la Condición de Refugiado. Ginebra. 
Vickers, L. (2008). Religious Freedom, Religious Discrimination and the Workplace. Oxford; Portland, Oregon: Hart.

Vickers, L. y European Commission (2007). Religion and Belief Discrimination in Employment: The EU Law. Luxembourg: Office for Official Publications of the European Communities.

Watson, P. y Oliver, P. (2019). Is the Court of Justice of the European Union Finding Its Religion? Fordham International Law Journal, 42 (3), 847-873.

Weiler, J. (2018). Je Suis Achbita! EJIL: Talk of the European Journal of International Law! [blog], 19-2-2018. Disponible en: https://bit.ly/37ZbKKd.

Williams, R. (2008). Civil and Religious Law in England: A Religious Perspective. Ecclesiastical Law Journal, 10 (03), 262-282. Disponible en: https://doi. org/10.1017/S0956618X08001403.

Zanini, S. (2019). El sacrificio sin aturdimiento previo no respeta suficientemente el bienestar de los animales: no a la etiqueta ecológica. Comentario de la sentencia del Tribunal de Justicia de 26 de febrero de 2019 en el asunto C-497/17. Derecho Animal (Forum of Animal Law Studies), 10 (2), 217-226. Disponible en: https://doi.org/10.5565/rev/da.432. 